Article

\title{
Superplastic Behavioral Characteristics of Fine-Grained 5A70 Aluminum Alloy
}

\author{
Sheng Li $\odot$, Zhongguo Huang $(\mathbb{D}$ and Shunyao Jin *(D) \\ School of Mechanical Engineering, University of Science and Technology Beijing, Beijing 100083, China; \\ lishengsir@163.com (S.L.); jsy_white@126.com (Z.H.) \\ * Correspondence: jinshunyao@ustb.edu.cn; Tel.: +86-010-6233-2467
}

Received: 18 December 2018; Accepted: 8 January 2019; Published: 10 January 2019

\begin{abstract}
A fine-grained 5A70 alloy sheet was obtained through a combination of rolling and heat treatment, with a total deformation reduction of $90 \%$ and an average grain size of $8.48 \mu \mathrm{m}$. The alloy was studied at $400,450,500$, and $550^{\circ} \mathrm{C}$ and exhibited excellent elongation-to-failures of 205, 321, 398 , and $437 \%$ with coefficients for the strain rate sensitivity of $0.42,0.40,0.47$ and 0.46 , respectively. Electron backscatter diffraction (EBSD) results revealed that the massive grain boundaries were high angle boundaries, suggesting that boundary sliding and grain rotation occurred during superplastic deformation. The X-ray diffraction (XRD) and energy dispersive spectrometer (EDS) results indicated that the compositions were the $\mathrm{Al}_{6}(\mathrm{MnFe})$ and $\mathrm{Mg}$-rich phase particles of the deformed $5 \mathrm{~A} 70$ alloy. In addition, the weakening of the pinning effect led to abnormal grain growth at 500 and $550{ }^{\circ} \mathrm{C}$, resulting in strain hardening. Transmission electron microscopy (TEM) examinations demonstrated that the applied stress at the head of the precipitated particles and/or grain boundaries exceeded the matrix-structure-promoted cavity nucleation. Cavities grew, interlinked, and coalesced, which resulted in crack formation that eventually led to superplastic fractures. Filaments formed at the fracture surfaces because of second phase precipitation at grain boundaries and the formation of Mg-rich oxides.
\end{abstract}

Keywords: 5A70 aluminum alloy; fine-grained structure; superplastic tension; grain boundary sliding; precipitated phase; strain hardening

\section{Introduction}

Due to the excellent combination of strength, corrosion resistance, weldability, formability, and low cost, Al-Mg alloys are widely used in the aircraft, shipbuilding, and automotive industries [1]. However, Al-Mg alloys are not heat treatable, so high strengths are achieved through solution hardening using the $\mathrm{Mg}$ atoms that are retained in the solid solution, through precipitation hardening from the second phase particles, or through strain hardening effects [2-5]. Accordingly, additional contents of alloying elements, $\mathrm{Mn}$, $\mathrm{Ti}$, and $\mathrm{Zr}$, refine the recrystallized grain size, while the $\mathrm{Cu}$ and $\mathrm{Mg}$ effectively improve the strength of Al-Mg alloys. The subcrystal and grain sizes of $\mathrm{Al}-\mathrm{Mg}$ alloys are refined with the increasing $\mathrm{Mg}$ concentration. Furthermore, recrystallization can promote the evolution of the grain orientation towards high-angle grain boundaries $[6,7]$. It is known that the increase in magnesium content (3-8.5\%) provides finer grains and improves the elongation-to-failure, $\delta$, in Al-Mg alloys [8-10].

Numerous domestic and literature studies have been conducted concerning different methods used to prepare Al-Mg alloys and investigations on their superplasticity in the preceding decades. The equal channel angular pressing (ECAP) [11-16] and friction stir welding/processing (FSW/FSP) [17-22] technologies were used to prepare the fine/ultrafine grain structure of Al-Mg alloys to investigate their superplasticity. For example, the 5083 alloy was prepared using the FSW method and its superplastic behavior was investigated in the temperature range from 250 to $450{ }^{\circ} \mathrm{C}$ [23]. The results 
revealed that reasonable superplasticity with an elongation-to-failure of $570 \%$ was achieved at $300{ }^{\circ} \mathrm{C}$ and $8.3 \times 10^{-3} \mathrm{~s}^{-1}$. In addition, the research regarding the superplasticity of Al-Mg alloys with an $\mathrm{Mg}$ content lower than $5.5 \mathrm{wt}$ \% and refined structure showed excellent elongation. With the development of the lightweight aviation industry and the requirements of sonic and supersonic aircraft, the superplastic form of aluminum alloy sheet metal can survive severe plastic deformations, reduce the weight, and increase the strength for complex structures. Therefore, high-strength Al-Mg alloys have significant advantages in stamping parts, including the fuselage, stringer, vertical tail skin, etc. [24]. It is well-known that a high $\mathrm{Mg}$ content enhances the strength of Al-Mg alloys; however, the precipitation of a large amount of $\mathrm{Mg}$-rich phase particles can lead to strain hardening in superplastic tension. The requirements for military, aluminum-alloy, superplastic sheet products are continually increasing, so the demand for rolling and heat treatment (RHT) methods to prepare superplastic sheets is urgent. In this paper, the RHT method will be used to obtain a fine-grained 5A70 alloy, mainly for large sheet metal parts in industrial applications.

Structural superplasticity is the ability of polycrystalline materials to exhibit high tensile elongations without the formation of a neck prior to fracture because of a high valued strain rate sensitivity, $m$ [25]. Strain rates during superplastic deformation with the fine-grained 5A70 alloy obey the following relationship [26-30]:

$$
\dot{\varepsilon}=A \frac{G D_{0} b}{k T}\left(\frac{b}{d}\right)^{p}\left(\frac{\sigma-\sigma_{0}}{G}\right)^{n} \exp \left(-\frac{Q}{R T}\right),
$$

where, $A$ is a dimensionless material constant; $b$ is the Burgers vector; $d$ is the grain size; $\sigma$ is the applied stress; $\sigma_{0}$ is the threshold stress; $G$ is the shear modulus; $k$ is Boltzmann's constant; $T$ is the absolute temperature; $p$ is the exponent of the inverse grain size, which ranges from 2 to $3 ; n$ is the stress exponent, which is defined as $1 / m ; D_{0}$ is a frequency factor; $Q$ is the activation energy; and $R$ is the gas constant. For the majority of superplastic materials, the rate-controlling process of superplastic deformation is grain boundary sliding (GBS) [31]. An analysis of the superplastic tension testing and surface observation showed that lattice diffusion dominated the GBS mechanism in superplastic tension of the 5A70 alloy. This mechanism, through the diffusion activation energy and the strain rate sensitivity, was defined as a constant rate with a temperature dependence of the fine-grained structure. Therefore, this study focused on revealing the superplastic behavior characteristics of the 5A70 alloy with fine-grained structures that depend on temperatures, strain rates, and precipitated phases during superplastic deformation.

\section{Materials and Methods}

The studied 5A70 alloy (correspond to GB/T 3190-2008 (China)), with a chemical composition of Al-5.72Mg-0.60Mn-0.058Cu-0.20Fe-0.080Si-0.095Zr-0.020Zn-0.043Ti (wt.\%), was fabricated using continuous casting. A differential scanning calorimeter (DSC) experiment was conducted using the processed sample on the SDT-Q600 thermo-analytical instrument (TA Instruments Inc., New Castle, PA, USA), and the curve was obtained at a heating rate of $5{ }^{\circ} \mathrm{C} / \mathrm{min}$ for the $5 \mathrm{~A} 70$ alloy immediately after solutionizing and natural aging. Meanwhile, the phase-transition temperature of the Al-5.7Mg alloy ranged from $255-575{ }^{\circ} \mathrm{C}$, according to the Al-Mg binary phase diagram shown in Figure 1b [32]. The DSC curve in Figure 1a shows two endothermic peaks. The result of the first endothermic peak clearly indicates the onset of incipient solid solution at $556{ }^{\circ} \mathrm{C}$, and the solid solution temperature of the $\beta$ phase particles was $581{ }^{\circ} \mathrm{C}$. The second endothermic peak demonstrates that the melting temperature of $5 \mathrm{~A} 70$ aluminum alloy was $631^{\circ} \mathrm{C}$.

The prepared experimental alloy ingot was homogenized and annealed at $450{ }^{\circ} \mathrm{C}$ for $40 \mathrm{~h}$. Then, the ingot alloy was rolled into a billet with a rectangular normal direction plane of $255 \mathrm{~mm} \times 255 \mathrm{~mm}$ at $380{ }^{\circ} \mathrm{C}$. A billet with a plate shape $(200 \mathrm{~mm} \times 200 \mathrm{~mm} \times 25 \mathrm{~mm})$ was processed from the state of the extruding ingot, and the natural aging treatment was $\geq 240 \mathrm{~h}$. The size and distribution of the precipitated phases in the smelted and forged processes were controlled to promote nucleation 
during dynamic recrystallization. The billet was subjected to 14 passes of cold rolling on a $350 \mathrm{~mm}$ reversing cold mill. In addition, full recrystallization at $340{ }^{\circ} \mathrm{C}$ was performed for $30 \mathrm{~min}$ using a GS-2-1200 box-type resistance furnace when the sheet was 10 and $5 \mathrm{~mm}$ thick. Ultimately, a $2 \mathrm{~mm}$ thick fine-grained 5A70 alloy superplastic sheet was obtained. Further details of the rolling process and the full recrystallization system were reported in a previous work [33].

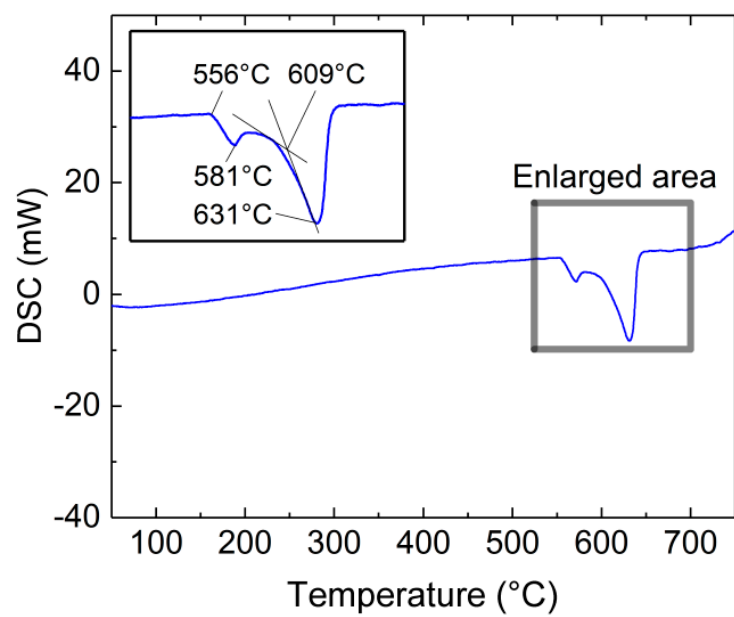

(a)

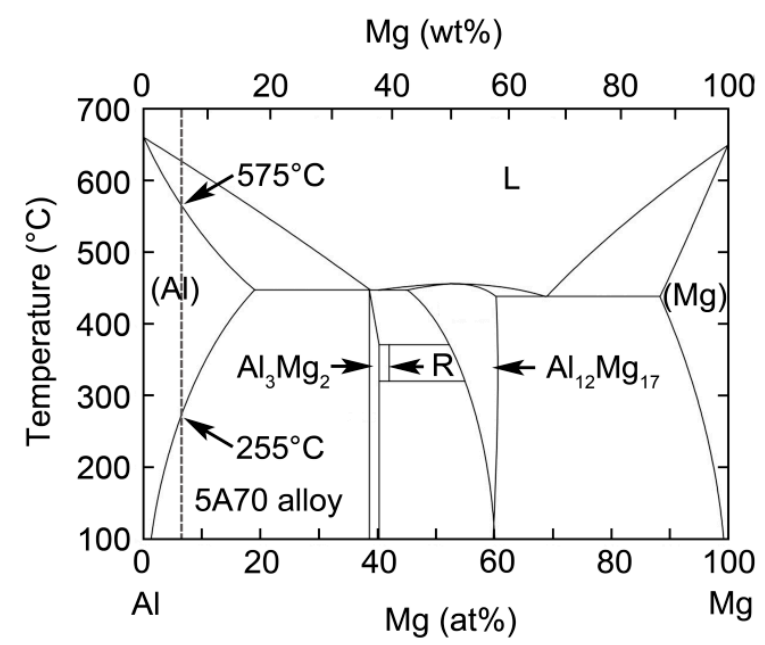

(b)

Figure 1. Differential scanning calorimeter (DSC) results of the $2 \mathrm{~mm}$ thick fine-grained 5A70 alloy (a) and the binary Al-Mg phase diagram (b).

Specimens with $8 \mathrm{~mm}$ gauge lengths and $4 \mathrm{~mm}$ gauge widths were machined along the parallel rolling direction. Superplastic tensile tests were performed on an AG-250KINC Instron machine (Shanghai Gold Casting Instrument Analysis Co., Ltd., Shanghai, China) with a microprocessor control pad in an NV63-CV high temperature furnace. The tests were performed at 400, 450, 500, and $550{ }^{\circ} \mathrm{C}$, and the initial strain rates were $5 \times 10^{-3}, 1 \times 10^{-3}$, and $5 \times 10^{-4} \mathrm{~s}^{-1}$ in air conditions. In addition, type-K thermocouples were used to detect the furnace temperature, which was controlled within approximately $\pm 2{ }^{\circ} \mathrm{C}$ along the entire gauge length during the tests. The specimen was insulated at $340{ }^{\circ} \mathrm{C}$ for $10 \mathrm{~min}$ for full recrystallization; moreover, the furnace can control the temperature equilibrium during the heating process. The same heating rate, $21^{\circ} \mathrm{C} / \mathrm{min}$, was utilized to reach the target temperature within $10 \mathrm{~min}$ and held for $2 \mathrm{~min}$ for stabilization.

Microstructural characterization and analysis of the 5A70 alloy were carried out using a Jeol-7100 (JEOL Ltd., Tokyo, Japan) transmission electron microscope (TEM), and a 600FEG (FEI Corporation, Hillsboro, OR, USA) scanning electron microscope (SEM). The average grain size was found using the linear intercept method with the OIM software (6.2.0 x86 version, EDAX Inc., Draper, UT, USA). The boundary orientation was measured by utilizing pixel-to-pixel measurements. To carry out the structural characterization in the SEM, specimens were cut into $5 \mathrm{~mm}$ sections near the superplastic fracture surface.

\section{Results}

\subsection{Initial Microstructures}

The $2 \mathrm{~mm}$ thick, deformed, superplastic sheet was fully recrystallized at $340{ }^{\circ} \mathrm{C}$ for $30 \mathrm{~min}$, while the total deformation was 90\% (20-2 mm). The electron backscatter diffraction (EBSD) map of the studied alloy based on the inverse pole figure coloring (insert) is shown in Figure 2. The average grain size of the fully recrystallized structure was $7.80 \mu \mathrm{m}$, the fraction of the high angle grain boundaries (HAGBs, $\theta \geq 15^{\circ}$ ) was 0.96 , and the average orientation angle was $38.0^{\circ}$ in the rolling direction (RD) plane, as shown in Figure 2a,d,e. Similarly, Figure $2 b, d$,e show the recrystallization structure along 
the normal direction (ND) plane. The average grain size was $8.4 \mu \mathrm{m}$, the HAGBs were 0.51 , and the average of the orientation angle was $19.4^{\circ}$. Figure $2 \mathrm{c}, \mathrm{d}, \mathrm{e}$ show the recrystallization structure along the transverse direction (TD) plane. The average grain size was $9.3 \mu \mathrm{m}$, the HAGBs were 0.85 , and the average of the orientation angle was $35^{\circ}$. The GBS can frequently take place during superplastic deformation because of the fine-grained structure and high fraction of the HAGBs in the initial microstructures.

Grain fragmentation followed by rolling deformation of new grains rapidly occurred in the original grain interiors after full recrystallization, as shown in Figure 2a-c. The new grains exhibited ultrafine equiaxed structures along the original boundaries. The grain size distributions were uniform over all planes, and most of the grain sizes ranged from 5 to $10 \mu \mathrm{m}$. However, the low angle grain boundaries (LAGBs, $\theta=2-15^{\circ}$ ) were as high as $57.4 \%$ in the ND plane whenever there was only 8.3 and $14.7 \%$ in the RD and TD planes, respectively. In summary, the larger the grain orientation angle and the higher the grain boundary index, the smaller the fine-grained size (average grain size $=\sqrt[3]{7.8 \times 8.4 \times 9.3}=8.48 \mu \mathrm{m})$.

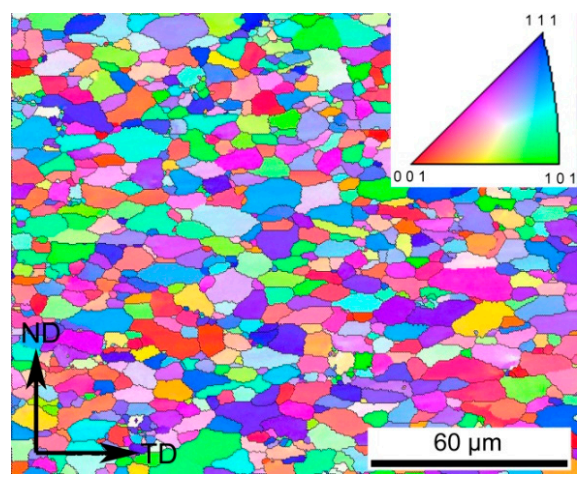

(a)

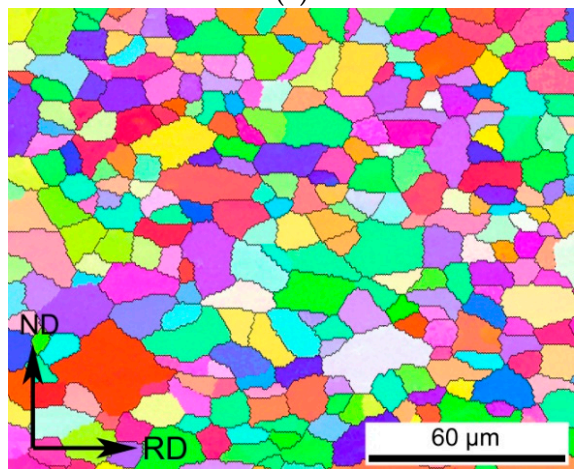

(c)

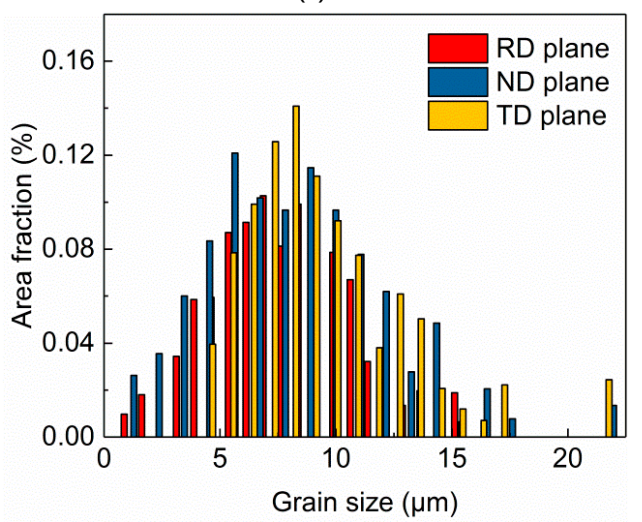

(d)

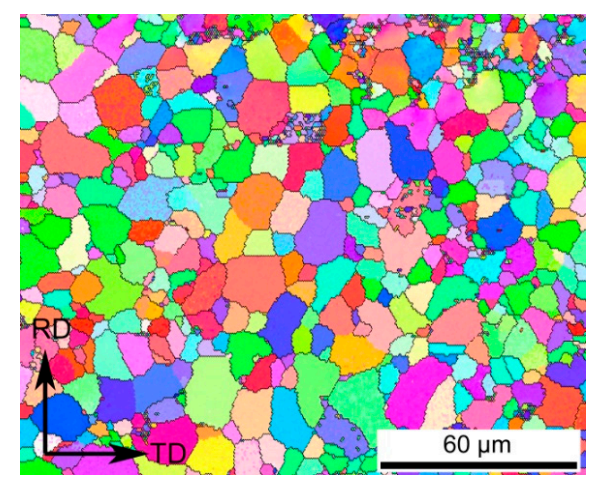

(b)

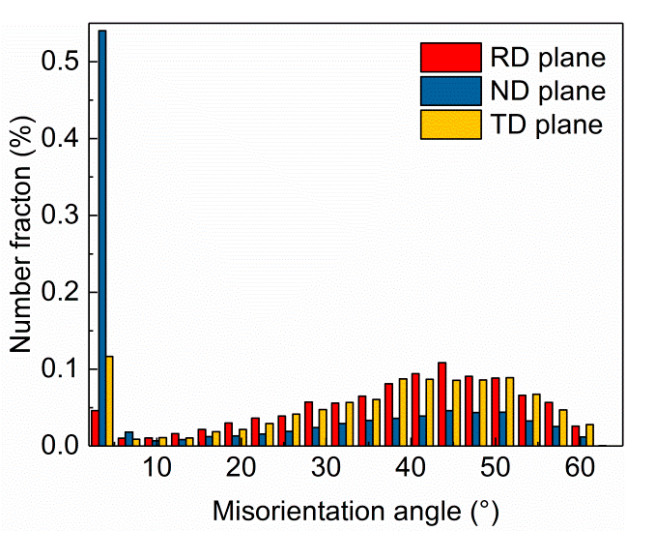

(e)

Figure 2. EBSD results of the grain size in the RD plane (a), ND plane (b), and TD plane (c); the grain size distribution (d); and the grain orientation angle (e) of the $2 \mathrm{~mm}$ thick fine-grained 5A70 alloy. 


\subsection{Superplastic Deformation Behaviors}

\subsubsection{Elongation-to-Failure}

Superplastic tensile tests focused on investigating the deformation mechanism at different temperatures, strain rates, and influences of the precipitated phases. The superplastic elongation-to-failure, $\delta$, results for the 5A70 alloy are shown in Figure 3.

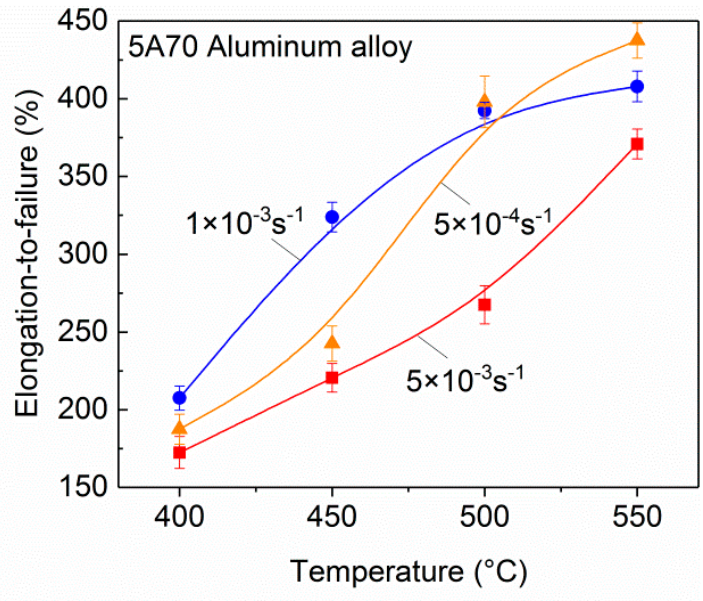

(a)

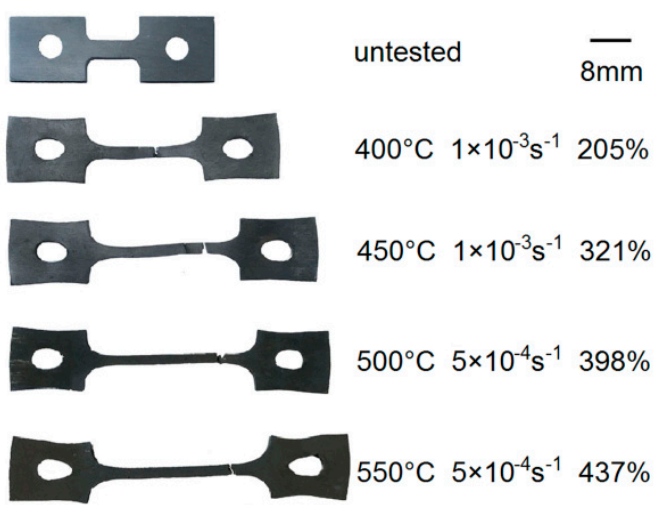

(b)

Figure 3. Superplastic elongation-to-failure results (a) and the specimens with excellent $\delta$ values at different temperatures, $400-550^{\circ} \mathrm{C}$, and different initial strain rates, $5 \times 10^{-4}-5 \times 10^{-3} \mathrm{~s}^{-1}$ (b).

Figure 3a shows that the elongation-to-failure increased gradually with increasing temperatures and decreasing initial strain rates. Figure $3 \mathrm{~b}$ shows that the samples were pulled to failure at different conditions, where the top image is the untested specimen. The 5A70 alloy exhibited reasonable $\delta$ values at 400 and $450^{\circ} \mathrm{C}$, with a moderate strain rate. However, excellent superplastic elongation-to-failures gave low strain rates at 500 and $550^{\circ} \mathrm{C}$, and the maximum $\delta$ value was $437 \%$ at $550{ }^{\circ} \mathrm{C}$ with $5 \times 10^{-4} \mathrm{~s}^{-1}$. In addition, necking was not visible in the superplastic fracture surface and a stable superplasticity elongation was exhibited simultaneously.

\subsubsection{True Strain-True Stress}

Figure 4 shows the superplastic tensile results for the true strain-true stress of the fine-grained 5 A70 alloy at $400-550^{\circ} \mathrm{C}$. At a constant temperature, the strain rate enhancement phenomenon of the materials was consistent with the general law of superplastic elongation characteristics and increased strain rate. The peak applied stress can be observed without the steady-state flow stage, which was the typical variation of the true stress-true strain behavior of the Al-Mg alloys [34-36]. The strain hardening was attributed to dislocation sliding/climbing. In addition, the dislocation density changed non-monotonically with the stable grain structure during the initial stages of superplastic deformation. A high dislocation density at the initial deformation for $T=400{ }^{\circ} \mathrm{C}$ with a high strain rate was caused by grain adaptation, i.e., the dislocation density increased rapidly and plugged in the grain, forming dislocation walls/cells and leading to an increased true stress. However, with the accumulation of deformation, the grain rotation occurred under shear stresses, and dislocations were absorbed by the grain boundaries, which led to the true stress remaining stable over a short period of time [37]. This is the reason that the true stress presented a step-up state. As the temperatures increased and the superplastic deformation accumulated, the true stress increased and the strain hardening gradually enhanced. At 500 and $550{ }^{\circ} \mathrm{C}$ with $5 \times 10^{-4} \mathrm{~s}^{-1}$, superplastic $\delta$ values achieved 398 and $437 \%$ due to the strong reduction of the unstable superplastic flow. However, the effect of diffusion creep was continuously strengthened as the deformation accumulated. The strong pinning effect declined 
because of the dissolution of the precipitated second phase particles, and the decreasing of the pinning effect led to abnormal grain growth during superplastic tensile. In addition, the completion of the grain rotation at the final tensile stage, which cannot balance the shear stress caused by the true stress, continually increased, as shown in Figure 4b.

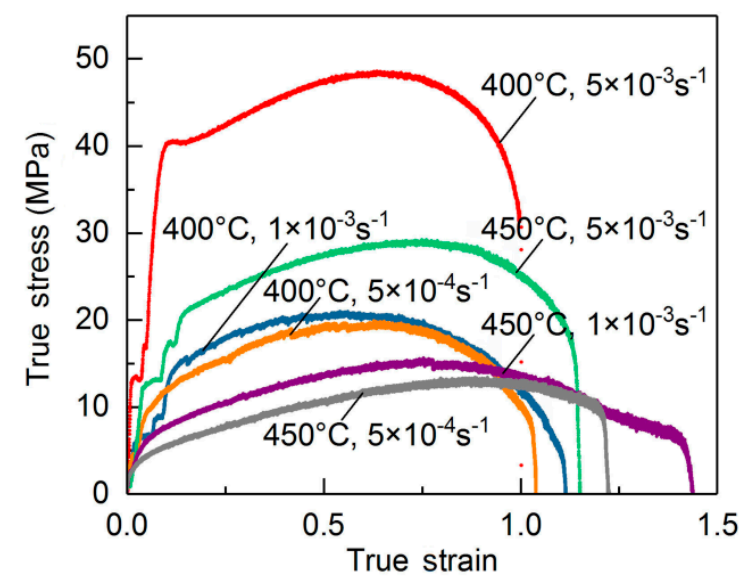

(a)

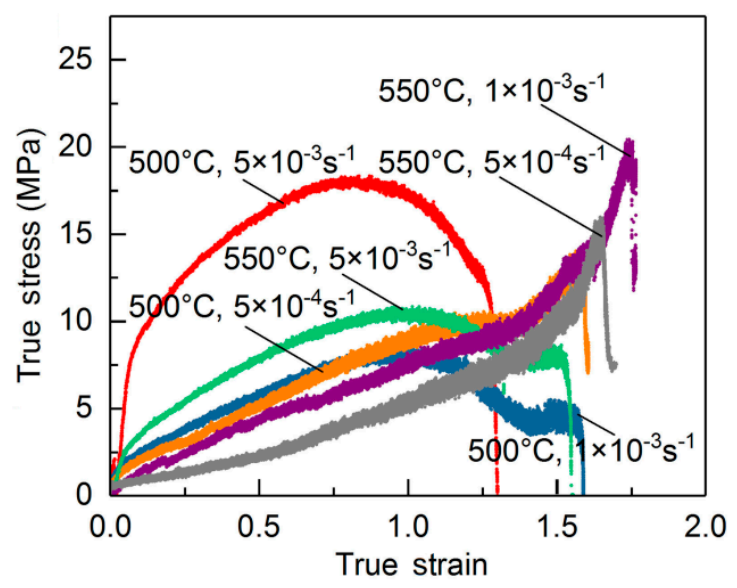

(b)

Figure 4. True strain-true stress results for the fine-grained 5A70 alloy at different temperatures: $400-450{ }^{\circ} \mathrm{C}(\mathbf{a})$ and $500-550{ }^{\circ} \mathrm{C}(\mathbf{b})$ with strain rates: $5 \times 10^{-3}-5 \times 10^{-4} \mathrm{~s}^{-1}$.

\subsubsection{Strain Rate Sensitivity}

The coefficient of strain rate sensitivity, $m$, indicates the capability of an alloy to resist necking spread and symbolizes the values of the superplastic elongation-to-failure. The $m$ value was derived as follows:

$$
m=\frac{\partial \ln \sigma}{\partial \ln \dot{\varepsilon}},
$$

The applied stress and strain rate data were plotted in the $\ln (\sigma)-\ln (\dot{\varepsilon})$ coordinate system. The coefficients of strain rate sensitivity at different temperatures and strain rates were obtained at $\varepsilon=0.6$ and are shown in Figure 5a. The variation of the $m$ values of the 5A70 alloy with the true strain in the superplastic deformation are shown in Figure $5 b$.

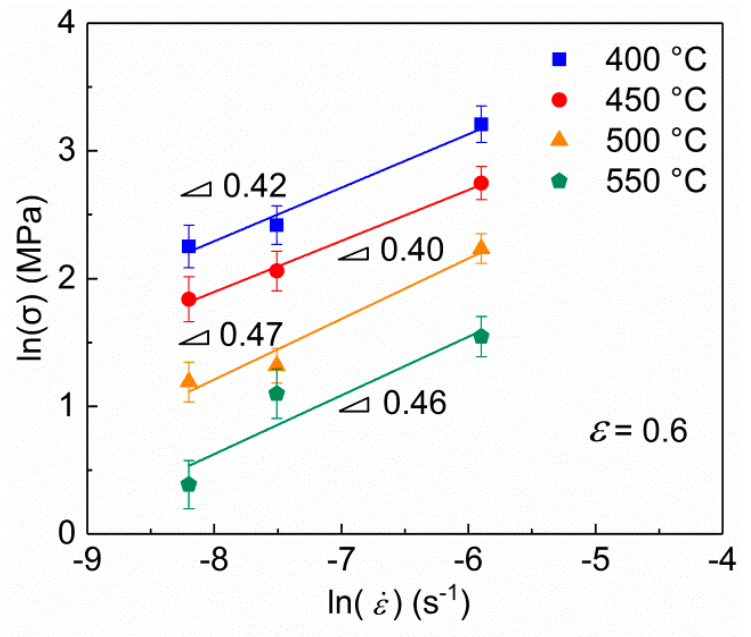

(a)

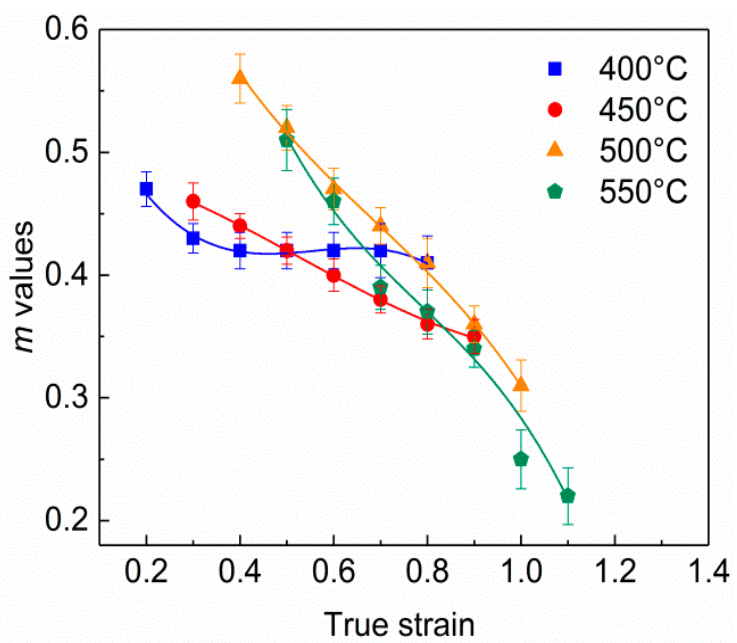

(b)

Figure 5. Coefficients of the strain rate sensitivity, $m$, at $\varepsilon=0.6$ (a) and the $m$ values during superplastic deformation at $400-550^{\circ} \mathrm{C}(\mathbf{b})$. 
It has been well-documented that the solute drag creep is the dominant deformation mechanism in the coarse-grained/fine-grained Al-Mg alloys at low temperatures and high strain rates [38]. The solute drag creep was previously characterized for $m \leq 0.33[39,40]$. However, the apparent $m$ values in the present study were generally higher than 0.33 and close to 0.5 . Thus, the solute drag creep might make a relatively limited contribution to the observed superplasticity. In addition, the corresponding stress exponent, $n$, values ranged from 2.13-2.50, which were close to the typical model for the superplasticity stress exponent $(n=2)$ [41]. Under the experimental temperatures and strain rates, the $m$ values declined with the accumulation of the deformation strain. Therefore, at 400 and $450{ }^{\circ} \mathrm{C}$, necking was prevented due to an extensive strain-hardening rate and the 5A70 alloy exhibited a moderate tensile ductility with $m \geq 0.33$. At 500 and $550{ }^{\circ} \mathrm{C}$, both strain hardening and the strain-hardening rates associated with decreased necking had low strain rates and high $\delta$ values.

\subsubsection{Activation Energy for Flow}

The activation energy for flow in superplastic deformation was used to assess the degree of difficulty of the material thermal deformation or for the rearrangement of atoms. The higher the dislocation density of the deformation alloy, the greater the activation energy. The activation energy, $Q$, was obtained by taking the logarithm of Equation (1) under constant strain rates. The apparent diffusion activation energy of $Q$ was derived as follows:

$$
Q=n R \frac{\partial \ln \left(\sigma-\sigma_{0}\right)}{\partial(1 / T)}
$$

The variation in the logarithmic stress as a function of reciprocal temperatures illustrates that a low strain rate appeared to be more sensitive to temperatures. The activation energy for flow, $Q$, ranged from 135 to $139 \mathrm{~kJ} / \mathrm{mol}$ and is illustrated in Figure 6. In addition, the lattice diffusion activation energy of $Q_{L}=143.4 \mathrm{~kJ} / \mathrm{mol}$ [42] and the grain boundary diffusion activation energy of $Q_{g b}=84.0 \mathrm{~kJ} / \mathrm{mol}$ [43] for pure aluminum demonstrated that lattice diffusion dominated the GBS diffusion processes. The activation energy for flow, $Q$, was $139 \mathrm{~kJ} / \mathrm{mol}$, and the maximum $\delta$ of $437 \%$ was obtained at $550{ }^{\circ} \mathrm{C}$ and $5 \times 10^{-4} \mathrm{~s}^{-1}$.

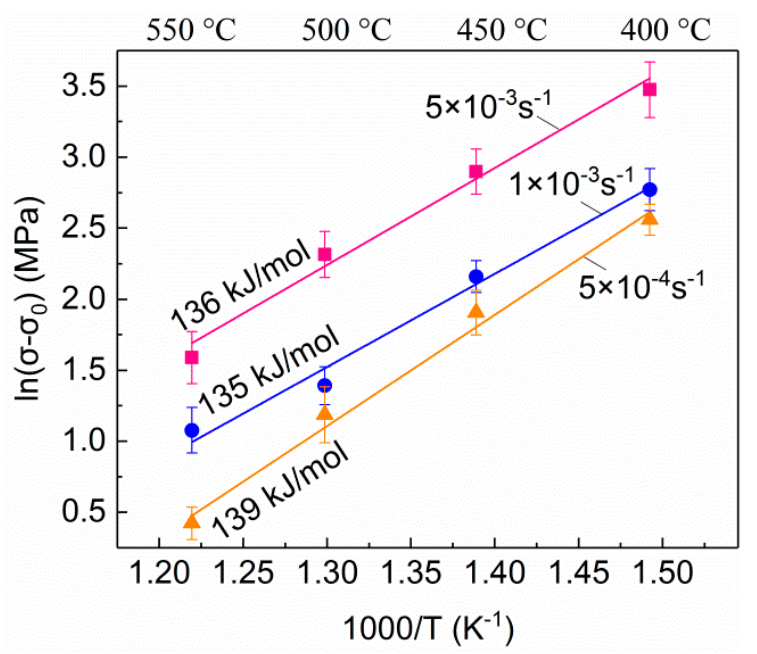

Figure 6. Logarithmic stress as a function of reciprocal temperatures and the apparent activation energy $Q$ of the fine-grained 5A70 alloy.

\subsection{Superplastic Fracture Surface Morphologies}

The superplastic fracture specimens were naturally aged, and the SEM results of the fracture surface morphologies at different temperatures and strain rates are shown in Figure 7. Fracture surfaces that formed under the GBS exhibited the characteristics of ductile failure at grain boundaries, and a 
large density of submicrometer filaments was evident on the fracture surfaces. Nevertheless, these filaments protruded from the fracture surface along the tensile direction. Similar sub-micrometer filaments were previously observed on the fracture surfaces of deformed superplastic alloys AA5083 [38] and AA7475 [44], as well as for aluminum-matrix composites [45].

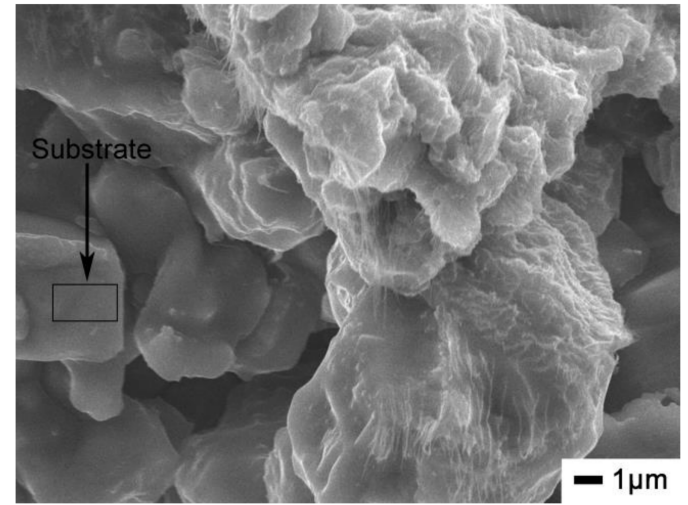

(a)

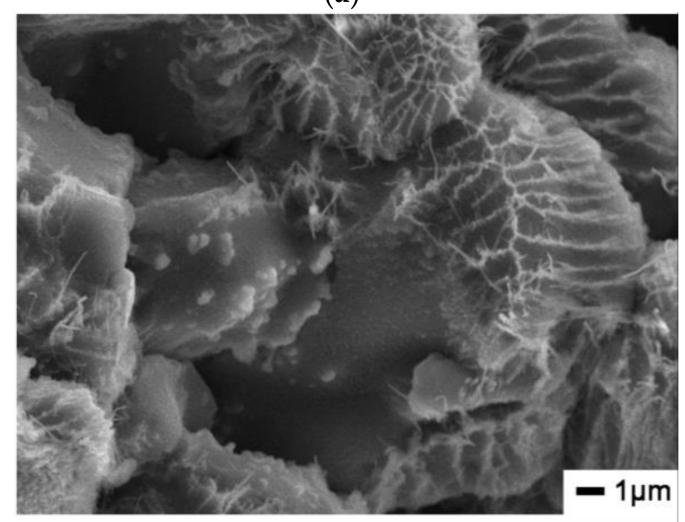

(c)

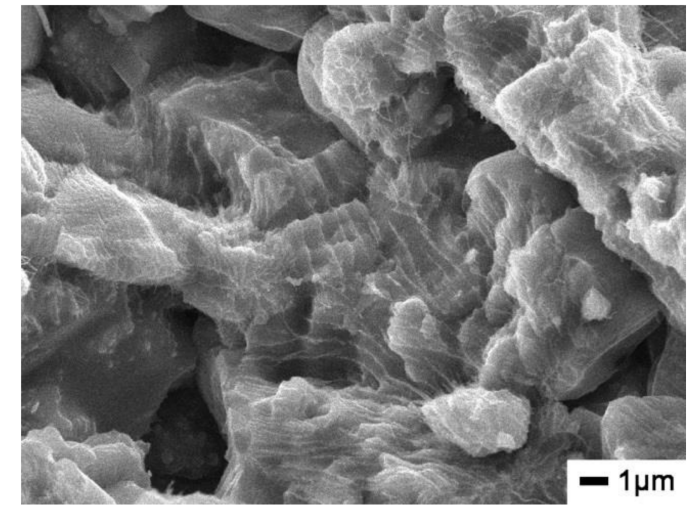

(b)

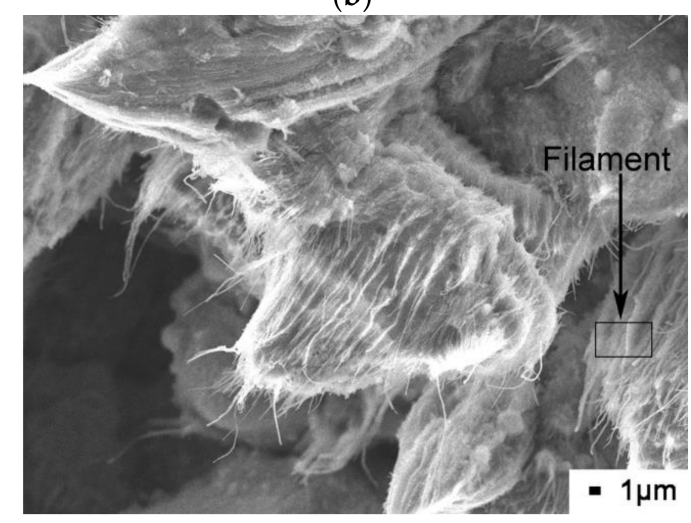

(d)

Figure 7. SEM micrograph of the superplastic fracture surface morphologies at $\mathrm{T}=400{ }^{\circ} \mathrm{C}$, $\dot{\varepsilon}=1 \times 10^{-3} \mathrm{~s}^{-1}(\mathbf{a}), T=450{ }^{\circ} \mathrm{C}, \dot{\varepsilon}=1 \times 10^{-3} \mathrm{~s}^{-1}$ (b) $, T=500{ }^{\circ} \mathrm{C}, \dot{\varepsilon}=5 \times 10^{-4} \mathrm{~s}^{-1}$ (c), and $\mathrm{T}=550{ }^{\circ} \mathrm{C}$, $\dot{\varepsilon}=5 \times 10^{-4} \mathrm{~s}^{-1}$ (d).

A variety of explanations have been reported for the origins of these sub-micrometer filaments. Superplastic tensile tests were performed below the temperature of the initial phase inversion $\left(T<556{ }^{\circ} \mathrm{C}\right)$. Therefore, the formation of filaments at $400{ }^{\circ} \mathrm{C}$ was actually due to sliding transitions from solute drag creeping to high angle grain boundaries. However, this cannot be from the incipient melting or the formation of a glassy phase at grain boundaries [46]. Figure 8, however, provides apparent evidence from which higher concentrations of magnesium and oxygen were observed on the fracture surfaces, indicating the formation of an Mg-rich oxide. Oxides were ridged on early exposed surface regions, as shown in Figure 8, with a composition similar to the filaments on the fracture surface. Ritchie et al. [47] reported that the $\mathrm{Mg}$-rich oxides $\mathrm{MgO}$ and $\mathrm{MgAl}_{2} \mathrm{O}_{4}$ were preferentially formed on Al-Mg alloys at $500{ }^{\circ} \mathrm{C}$. Chang et al. [48] confirmed that filaments were observed at the fracture surfaces when the specimen was tested in air rather than under vacuum conditions.

Previous works observed that filament formation occurred in AA5083 within the cracks in the tribolayers that correspond to locations above the grain boundaries of the near-surface subjected to the GBS at $\mathrm{T}>300{ }^{\circ} \mathrm{C}[49,50]$. Consequently, the $\mathrm{Mg}_{5} \mathrm{Si}_{6}$ phase precipitated at the grain boundaries. This was the reason for the increased Si content from 2.95 (in the substrate) to 11.69 wt.\% (in the filaments). In addition, the $\mathrm{Mg}_{5} \mathrm{Si}_{6}$ phase particles that precipitated along the grain boundaries and dominated the filament formation were the result of grain boundary sliding during superplastic deformation. Therefore, this is a reasonable explanation for the increased Si content in the filaments. 
These results suggest that the formation of sub-micrometer filaments of the fine-grained 5A70 alloy during superplastic deformation occurred from the growth of Mg-rich oxides and precipitated second phases at the grain boundaries.

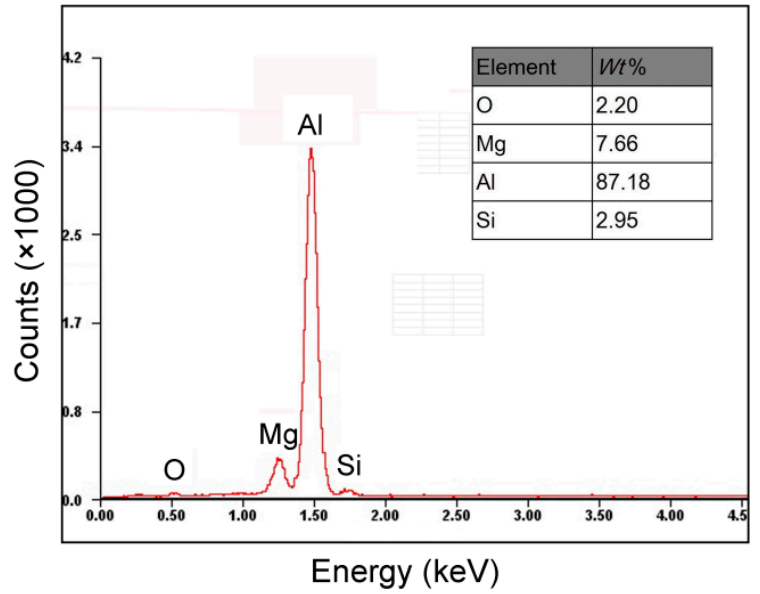

(a)

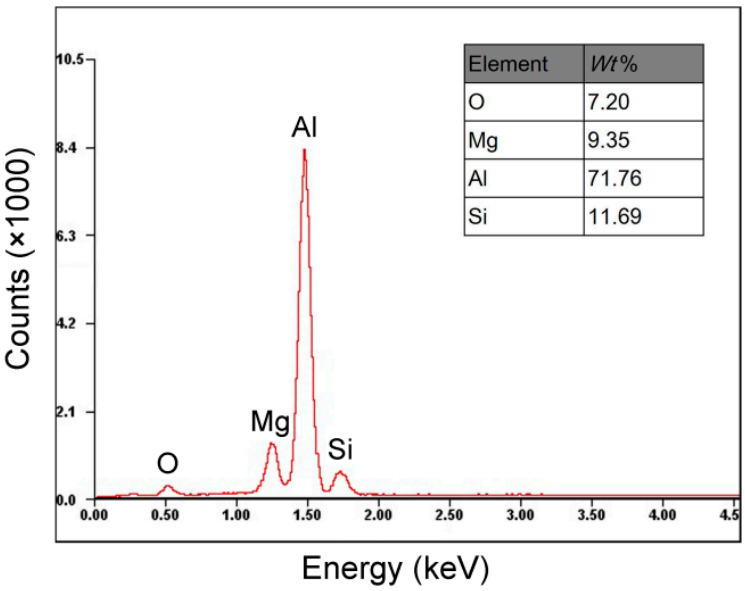

(b)

Figure 8. EDS analysis for the superplastic fracture surface of the substrate (a) and the filaments (b) of the fine-grained $5 \mathrm{~A} 70$ alloy.

\section{Discussion}

\subsection{Influence of Plastic Flow during Superplastic Deformation}

It is known that strain hardening and/or the strain-hardening rate can provide the plastic stability during superplastic tensile, defined by:

$$
\sigma=K_{1} \dot{\varepsilon}^{m} \varepsilon^{n_{1}},
$$

where, $K_{1}$ is a constant, and $n_{1}$ is the coefficient of strain hardening. A logarithmic analysis of Equation (4) showed that $n_{1}=d l n \sigma / d \ln \varepsilon$ was calculated by taking the true stress and strain rates of the true strain, $\varepsilon=0.3-0.7$, in the superplastic ductility, and the resulting $n_{1}$ values are shown in Table 1 .

Table 1. Coefficients of strain hardening at different temperatures and strain rates.

\begin{tabular}{|c|c|c|c|c|c|c|c|}
\hline $\begin{array}{c}\text { Temperature } \\
T /{ }^{\circ} \mathrm{C}\end{array}$ & $\begin{array}{l}\text { Strain } \\
\text { Rate } \\
\dot{\varepsilon} / s^{-1}\end{array}$ & $\begin{array}{c}\text { Strain } \\
\text { Hardening } \\
\text { Coefficient } / n_{1}\end{array}$ & $\begin{array}{c}\text { Standard } \\
\text { Deviation/\% }\end{array}$ & $\begin{array}{c}\text { Temperature } \\
T /{ }^{\circ} \mathrm{C}\end{array}$ & $\begin{array}{l}\text { Strain } \\
\text { Rate } \\
\dot{\varepsilon} / s^{-1}\end{array}$ & $\begin{array}{c}\text { Strain } \\
\text { Hardening } \\
\text { Coefficient } / n_{1}\end{array}$ & $\begin{array}{c}\text { Standard } \\
\text { Deviation/\% }\end{array}$ \\
\hline \multirow{3}{*}{400} & $5 \times 10^{-3}$ & 0.14 & 0.75 & \multirow{3}{*}{500} & $5 \times 10^{-3}$ & 0.34 & 1.38 \\
\hline & $1 \times 10^{-3}$ & 0.16 & 0.72 & & $1 \times 10^{-3}$ & 0.61 & 3.86 \\
\hline & $5 \times 10^{-4}$ & 0.24 & 0.84 & & $5 \times 10^{-4}$ & 0.79 & 2.23 \\
\hline \multirow{3}{*}{450} & $5 \times 10^{-3}$ & 0.23 & 1.26 & \multirow{3}{*}{550} & $5 \times 10^{-3}$ & 0.55 & 2.20 \\
\hline & $1 \times 10^{-3}$ & 0.38 & 1.88 & & $1 \times 10^{-3}$ & 0.69 & 3.98 \\
\hline & $5 \times 10^{-4}$ & 0.46 & 1.54 & & $5 \times 10^{-4}$ & 0.75 & 2.78 \\
\hline
\end{tabular}

There is no strain hardening in traditional superplastic materials [51]. In contrast, the 5A70 alloy showed extensive initial strain hardening, similar to other aluminum alloys with fine-grained structures [52]. In particular, the strain hardening at high temperatures and low strain rates is shown in Figure $4 \mathrm{~b}$, which significantly contributed to the elongation-to-failure of the superplastic tensile because the coefficient of strain rate sensitivity $m$ was greater than 0.33 . The increased dislocation density in the crystal lattice and the distortion of the grain structure were the main reasons for the strain hardening [53]. These $m$ values were not sufficient to stop unstable plastic flow because of the pure strain rate hardening. However, the coefficient of strain hardening was relatively high (Table 1), and the strain hardening attributed to grain coarsening provided unstable plastic flow. Since the true strain rate declined with the accumulated strain, the $m$ values provided a uniform deformation that 
was visible within the gauge length up to the fracture during the strain-softening stage (Figure 3). The initial strain hardening in the superplastic flow stage provided stability of the plastic flow at the initial stage, with high $m$ values.

The temperature-controlled shear modulus $G(\mathrm{MPa})$ of pure aluminum, $G=\left(3.022 \times 10^{4}\right)-16 \mathrm{~T}$, was used [54]. Equation (1) with $p=2$ and $n=2$ is typically used to describe the superplastic flow of aluminum alloys with grains in the range of 1-10 $\mu \mathrm{m}[55]$ :

$$
\sigma=\sqrt{\frac{G k T}{A D_{g b}}} \frac{d}{b^{3 / 2}} \dot{\varepsilon}^{1 / 2}
$$

A plot of $\sigma$ against $\dot{\varepsilon}^{1 / 2}$ using double linear scales was adopted to determine the threshold stress. Using the superplastic data gave the best linear fit for the assumed stress exponents for all the investigated temperatures. Therefore, all the values for the threshold stress were estimated by extrapolating the data to zero strain rates using rectilinear regression, as illustrated in Figure 9. The calculated threshold stresses were highly dependent on the deformation temperatures, as summarized in Table 2. The results demonstrated that the threshold stress was associated with a high density of dispersed particles, which impeded the movement of dislocations and grain boundaries during superplastic deformation. For the studied fine-grained 5A70 alloy, the $m$ values tend to increase with increasing strain rate over temperatures ranging from 400 to $550{ }^{\circ} \mathrm{C}$. Similarly, the decreased $m$ value of the strain accumulation and the reduced superplastic flow stress led to the superplastic fracture.

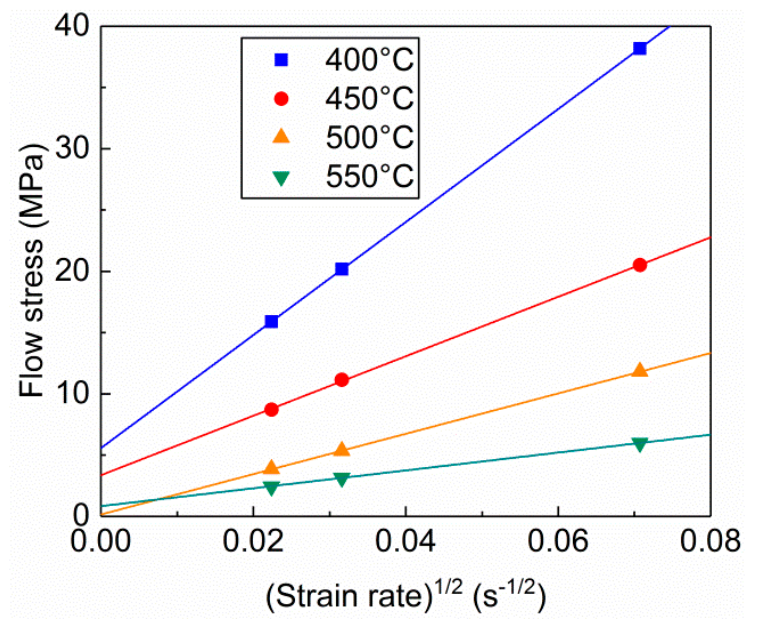

Figure 9. Variation of the flow stress as a function of $\dot{\varepsilon}^{1 / 2}$ for the fine-grained 5A70 alloy subjected to RHT.

Table 2. Threshold stress of RHT 5A70 alloy at the studied temperatures.

\begin{tabular}{ccccc}
\hline Temperature $\left({ }^{\circ} \mathrm{C}\right)$ & 400 & 450 & 500 & 550 \\
\hline Threshold stress $(\mathrm{MPa})$ & 5.56 & 3.35 & 0.15 & 0.83 \\
\hline
\end{tabular}

The GBS was closely related to the microstructure recrystallization. In this case, the fine-grained structure and the aberration transformation of the lattice distortion produced by the dislocation slipping/climbing allowed the strain hardening rate to be eliminated during superplastic deformation. In addition, the full recrystallization of the deformed structure evidently does not attenuate the strain hardening. In contrast to the adopted true strain, the $m$ values ranged from 0.56 to 0.38 , as illustrated in Figure 5b. Nevertheless, the strain hardening occurred in the last stage of the formation, as shown in Figure $4 b$, and the strain hardening coefficients were 0.61 and 0.55 , as shown in Table 1 . Moreover, the strain hardening intensified during the superplastic deformation and corresponded to the coefficients 
of strain hardening of $n_{1}=0.79,0.89$ and 0.75 . Meanwhile, it was not sufficient to compensate for extensive strain hardening at $m \leq 0.33$, and the true stress under superplastic tensile began to show a general increase. However, the unstable superplastic flow occurred up to $n_{1} \leq 0.50$ without strain hardening, as shown in Figure 4a. The superplastic fracture for the fine-grained 5A70 alloy was accompanied by a sharp decline in the deformation and unsteady flow stresses for the strain hardening and strain rate sensitivity at high temperatures.

The influence of temperature and grain size on the diffusion coefficient during the superplastic deformation process in the typical superplastic flow theory of fine-grained alloys was proven through experiments. The effect of the diffusion process was related to the effective diffusion coefficient $D_{\text {eff }}$, which included the lattice diffusion coefficient, $D_{L}$, and the grain boundary diffusion coefficient, $D_{g b}$, whose effective diffusion coefficient is defined as follows [56]:

$$
D_{e f f}=D_{L}+x \frac{\pi w}{d} D_{g b}
$$

where $x$ is a constant equal to $1.7 \times 10^{-2}$ and $w$ is the grain boundary width $(w=2 b$ and $b=2.863 \times 10^{-10} \mathrm{~m}$ ) [30]. Equation (6) indicates that the two diffusion paths were independent, and both $D_{g b}$ and $D_{L}$ contribute simultaneously to the superplastic deformation. As is well-known, the $D_{L}$ of pure aluminum is $D_{L}\left(\mathrm{~m}^{2} / \mathrm{s}\right)=1.86 \times 10^{-4} \exp (-143400 / \mathrm{RT})$, and the $D_{g b}$ of pure aluminum is $D_{g b}\left(\mathrm{~m}^{2} / \mathrm{s}\right)=10^{-4} \exp (-84000 / \mathrm{RT})$ [41]. In this study, at 400 and $550{ }^{\circ} \mathrm{C}$, using the Equation: $\varphi=x(\pi w / d)\left(D_{g b} / D_{L}\right), \varphi=0.022-0.085<1$ was obtained. Therefore, the dominant diffusion mechanism at the temperature range from 400 to $550{ }^{\circ} \mathrm{C}$ was lattice diffusion.

\subsection{Effect of Temperature on the Grain Growth and Superplastic Behavior}

Equation (1) shows that with a constant strain rate, the superplastic elongation temperature is inversely proportional to the $n$-th power of the true strain. That is, the higher the temperature, the longer the true strain of the superplastic $\delta$ value. Meanwhile, the true stress evidently declines. Figure 10 shows the EBSD analyses of the 5A70 alloy deformed at different temperatures for $\dot{\varepsilon}=1 \times 10^{-3} \mathrm{~s}^{-1}$ after the superplastic fracture. The color of each grain was coded by its crystal orientation based on the [001] inverse pole figure in Figure 10a. The aggregation of a large number of ultrafine grains was near the small cavities in the tensile specimen. In addition, the cavity interlinkage and coalescence were precisely identified via the supporting microscopy evidence. Nevertheless, new ultrafine grains occurred in the limited region and were generated near the initial deformed grains, indicating that dynamic recrystallization occurred. Compared with the microstructures of the sample before deformation (Figure $2 b$ ), it can be inferred from Figure 10a-d that the grains were gradually elongated in the tensile direction as the temperature increased.

Figure $10 \mathrm{a}-\mathrm{d}$ show that the microstructure mainly consists of grain sizes that were larger than $10 \mu \mathrm{m}$. Dynamic recrystallization occurred during superplastic deformation, which generated the recrystallized grains. At $400{ }^{\circ} \mathrm{C}$ and $1 \times 10^{3} \mathrm{~s}^{-1}$, dynamic recrystallization occurred without obvious grain growth, giving a grain size of $9.60 \mu \mathrm{m}$. The grain boundary character distribution data and average grain sizes of the samples in Figure 10 are listed in Table 3. Compared with Figure 2b, it can be observed that the recrystallized grains gradually coarsen when increasing the deformation temperatures or increasing the deformation degree. However, the final grain structure had an average recrystallized grain size of less than $15 \mu \mathrm{m}$ for $400-500{ }^{\circ} \mathrm{C}$ in this work, revealing that the $5 \mathrm{~A} 70$ alloy had a strong ability to inhibit the grain growth during superplastic deformation. The proportion of the LAGBs fraction at 400,450, and $500{ }^{\circ} \mathrm{C}$ gradually increased from 11.4 to 16.4 and $22.8 \%$, but decreased to $18.5 \%$ at $550{ }^{\circ} \mathrm{C}$. In contrast, the corresponding grain boundary angle decreased initially and then increased, which was due to the distorted grain structure at $550{ }^{\circ} \mathrm{C}$. These fractions indicated that most boundaries were at high-angles, which can indirectly prove the occurrence of grain boundary or interphase boundary sliding. Nevertheless, the abnormal grain growth led to an increased LAGBs and grain misorientation angle, as shown in Figure 10d,h. The grain boundary sliding along the 
[110] crystal direction and the orientation grain boundary angle account for more than 50\% during the superplastic deformation. Sakai et al. [57] found that the accompanying grain refinement and grain boundary rotation from the large flow softening took place due to the operation of GBS at low strain rates. However, it is known that the glide plane of the face-centered cubic structure in the 5A70 alloy is $\{111\}$, and the grain boundary slip direction is $<110>$ [58]. This demonstrates that the sliding mainly took place in the slip direction to balance the grain-to-grain deformation and the reaction stress during superplastic tensile. It is noted that there was positive evidence for the grain rotation and grain boundary sliding for the 5A70 alloy during superplastic deformation.

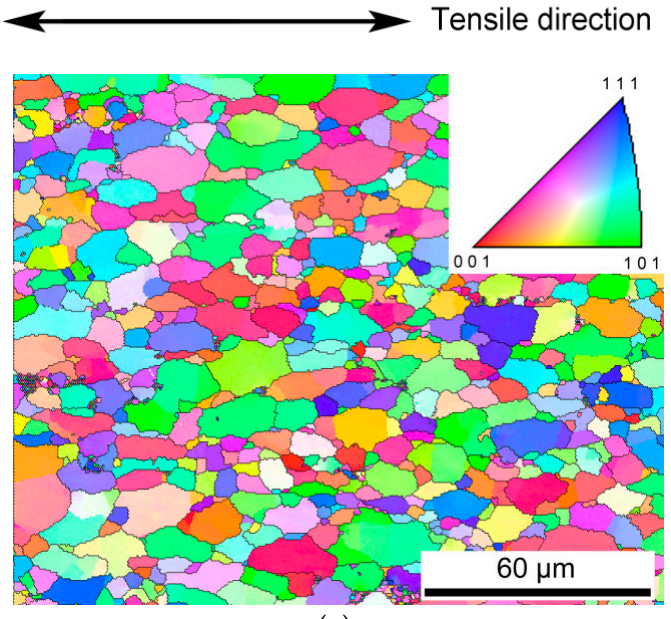

(a)

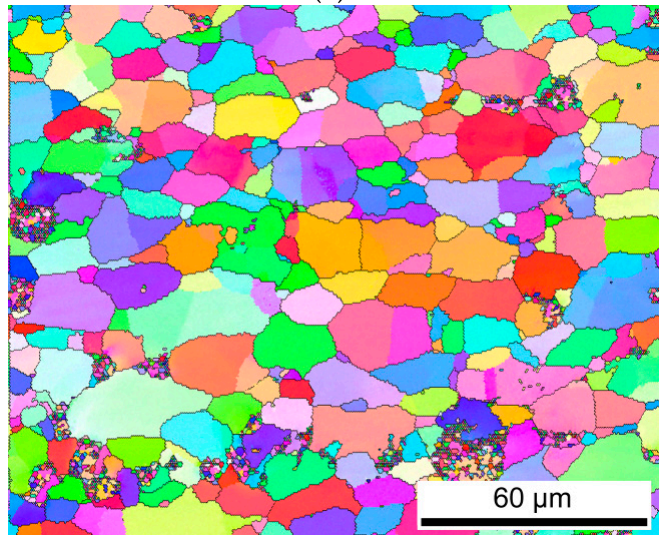

(b)

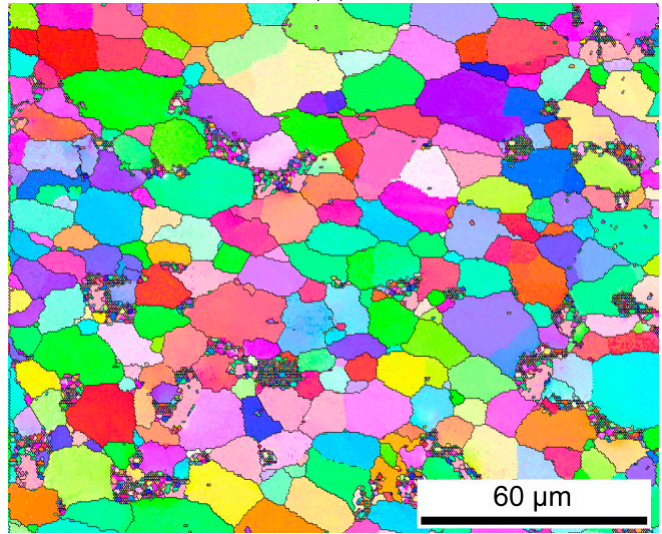

(c)

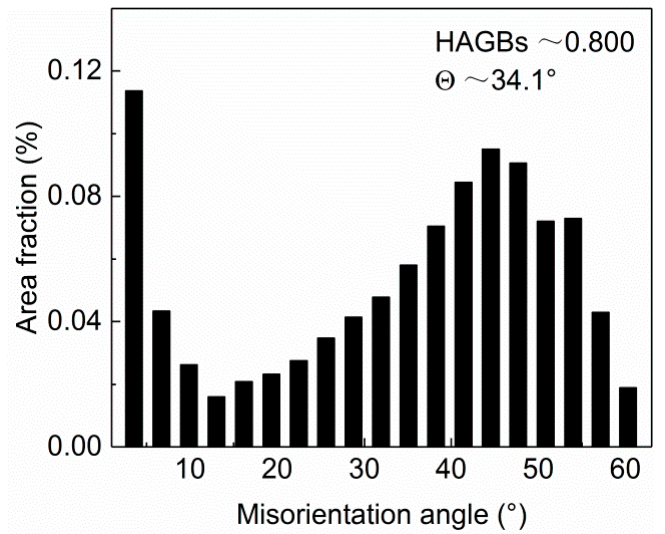

(e)

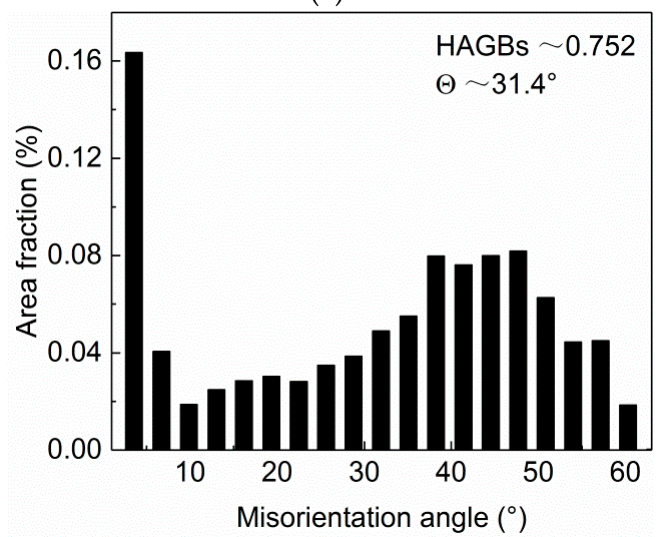

(f)

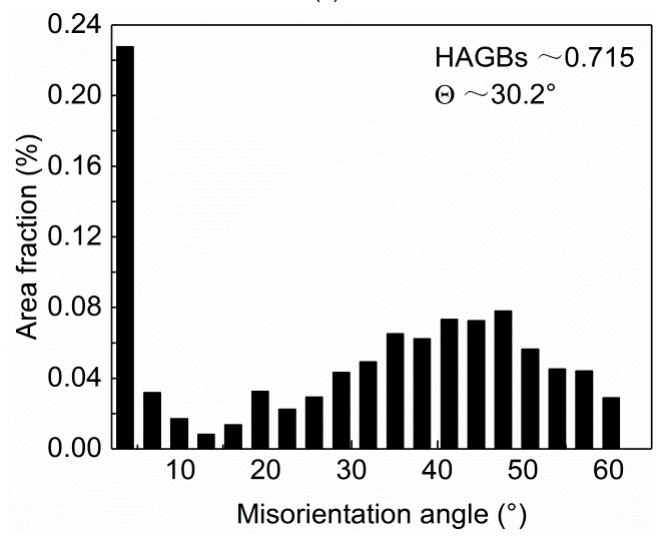

(g)

Figure 10. Cont. 


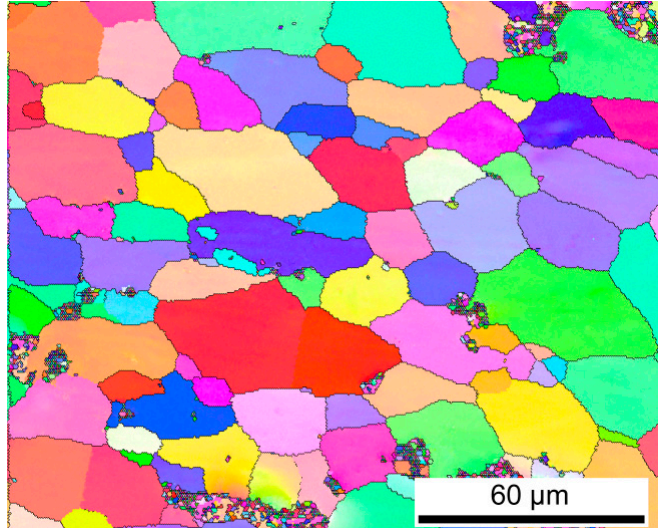

(d)

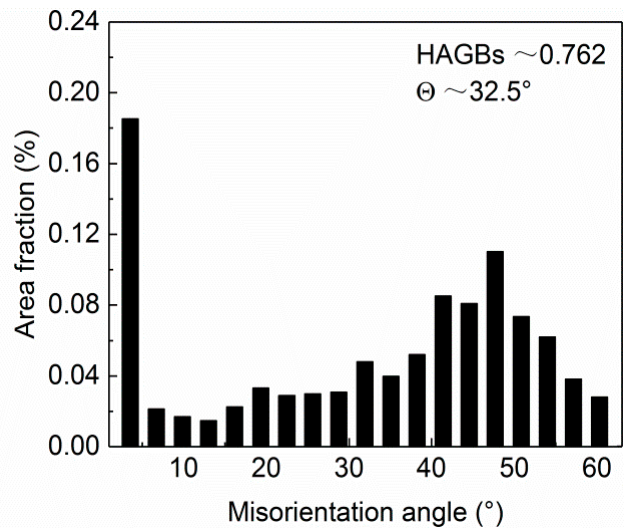

(h)

Figure 10. Influence of the temperature on the grain growth in the deformation process at $400{ }^{\circ} \mathrm{C}$ with $\dot{\varepsilon}=1 \times 10^{-3} \mathrm{~s}^{-1}$, where the grain and orientation angle are shown in $(\mathbf{a}, \mathbf{e})$, as well as $450^{\circ} \mathrm{C}$ in $(\mathbf{b}, \mathbf{f})$, $500{ }^{\circ} \mathrm{C}$ in $(\mathbf{c}, \mathbf{g})$, and $550{ }^{\circ} \mathrm{C}$ in $(\mathbf{d}, \mathbf{h})$.

The grain growth of the fine-grained structure was based on the initial grain size during the fully dynamic recrystallization, which includes the static growth of the grain over a certain period of time, and the grain size increased under superplastic tensile. Therefore, the total grain growth during superplasticity is defined as $d D=\left(\partial D_{t} / \partial t\right) d t+\left(\partial D_{\varepsilon} / \partial \varepsilon\right) d \varepsilon$. Sato et al. [59] proposed the deformation induced grain growth (DIGG) model as: $\ln \left(D / D_{0}\right)=\alpha \varepsilon$. Based on the grain growth model introduced by Cao [60], the superplastic deformation grain growth model at a constant rate is shown as follows [61]:

$$
d=\left[d_{0}^{q} \exp (\alpha q \varepsilon)+\left(K /\left(\alpha q \dot{\varepsilon}_{0}\right)\right) \exp \varepsilon(\exp (\alpha q \varepsilon)-1)\right]^{1 / q}
$$

where, $d$ is the grain size at the tensile time $t, d_{0}$ is the initial grain size, $\alpha$ is the grain growth exponent, $q$ is the growth exponent, $\varepsilon$ is the true strain, $K$ is the grain growth rate constant, and $\dot{\varepsilon}_{0}$ is the initial strain rate. Then, the relation: $\phi=w D_{g b} /\left(D_{0} D_{L}\right)$ is used, where $w$ is the grain boundary width. Malopheyev et al. [62] obtained the value for the diffusion coefficient: at $400-550{ }^{\circ} \mathrm{C}$, the calculated available $\phi=0.02-0.13<1$. Therefore, the lattice diffusion growth dominated the grain growth mechanism, where $q=3$ [63]. The growth rate factor, $K$, was obtained with the temperature changes and strain rates shown in Table 3.

Table 3. Analysis of the grain growth for the superplastic fracture surfaces.

\begin{tabular}{cccccc}
\hline $\begin{array}{c}\text { Temperature } \\
\mathbf{T} /{ }^{\circ} \mathbf{C}\end{array}$ & Strain Rate $\dot{\varepsilon} / \mathbf{s}^{-\mathbf{1}}$ & $\begin{array}{c}\text { True Strain } \\
\boldsymbol{\varepsilon} / \mathbf{M P a}\end{array}$ & $\begin{array}{c}\text { Experimental } \\
\text { Results } \boldsymbol{d} / \boldsymbol{\mu m}\end{array}$ & $\begin{array}{c}\text { Proportional } \\
\text { Constant } \boldsymbol{\alpha}\end{array}$ & $\begin{array}{c}\text { Growth Rate } \\
\text { Factor }\left(\times \mathbf{1 0}^{-\mathbf{2 1}}\right) \\
\mathbf{K} / \mathbf{m}^{\mathbf{3}} \mathbf{s}^{-\mathbf{1}}\end{array}$ \\
\hline 400 & & 1.13 & 9.60 & 0.18 & 2.32 \\
450 & $1 \times 10^{-3}$ & 1.45 & 11.78 & 0.28 & 2.53 \\
500 & & 1.60 & 13.32 & 0.33 & 2.58 \\
550 & 1.61 & 21.16 & 0.61 & 8.94 \\
\hline 500 & \multirow{2}{*}{$5 \times 10^{-4}$} & 1.76 & 14.35 & 0.34 & 3.42 \\
550 & 1.71 & 24.26 & 0.66 & 3.47 \\
\hline
\end{tabular}

For temperatures of $400-500{ }^{\circ} \mathrm{C}$, growth of the lattice diffusion promoted the grain structure distortion energy for the grain growth during superplastic deformation. Namely, grain growth along the lattice diffusion of the polymerization growth factors was $\alpha=0.18-0.34$, and the grain growth rate was $K=2.32 \times 10^{-21}-3.42 \times 10^{-21} \mathrm{~m}^{3} / \mathrm{s}$. This is because the dynamic recrystallization of the deformed structure is a function of the pinning effect of the precipitated particles. Moreover, the grain growth occurred towards the tensile direction as the tensile deformation was accumulated. At $550{ }^{\circ} \mathrm{C}$, the lattice diffusion of the polymerization growth factors was $\alpha=0.61$ and 0.66 . The abnormal grain growth 
was due to the weakening of the pinning effect from the dissolution of the precipitated particles, which were unable to effectively inhibit the grain growth during dynamic recrystallization [64]. In addition, the deformed distortion structure had a pronounced orientation along the tensile direction. Therefore, the grain growth exponent, $\alpha$, indicates the influence of the dynamic grain growth for the 5A70 alloy superplasticity. Furthermore, the superplastic tensile of the 5A70 alloy exhibited a strong temperature dependence. This clearly clarified that the strain hardening was due to the distortion of the grain structure during dynamic recrystallization.

The lattice diffusion dominated the mechanism of the GBS-induced grain to rotate the slip surface under an applied stress and balance the stress tensor to maintain the superplastic flow. At $T=500{ }^{\circ} \mathrm{C}$, the decreased precipitated particles played a significant role in promoting the recrystallized grain growth, which resulted in abnormal grain growth.

\subsection{Influence of Mg-Rich Phase Particles on Superplastic Tensile and Fracture Process}

At $500{ }^{\circ} \mathrm{C}$ and $1 \times 10^{3} \mathrm{~s}^{-1}$, the components of the precipitated phase were analyzed using X-ray diffraction (XRD) and energy dispersive spectrometry (EDS), as shown in Figure 11. Full recrystallization of the deformed fine-grained 5A70 alloy structure after cold rolling was obtained using heat treatment. Figure 11a shows the dispersive fine precipitates in the recrystallized structure of the rolling surface. In addition, Figure $11 \mathrm{~b}$ shows the results of the particle determination for the superplastic fracture specimens. There was a transition between the metastable $\beta-\mathrm{Al}_{2} \mathrm{Mg}$ phase and the $\beta-\mathrm{Al}_{3} \mathrm{Mg}_{2}$ phase with a hexagonal structure in the dynamic stretching process, as shown in Figure 11c [65]. Figure 11b,d indicate that the $\mathrm{Al}_{6}(\mathrm{MnFe})$ phase disperses after all the heat treatments [30,66], and the $\mathrm{Mg}_{5} \mathrm{Si}_{6}$ phase precipitated during the superplastic deformation. Similar dispersed phase particles were previously observed in the aluminum-magnesium-silicon alloys [67,68].

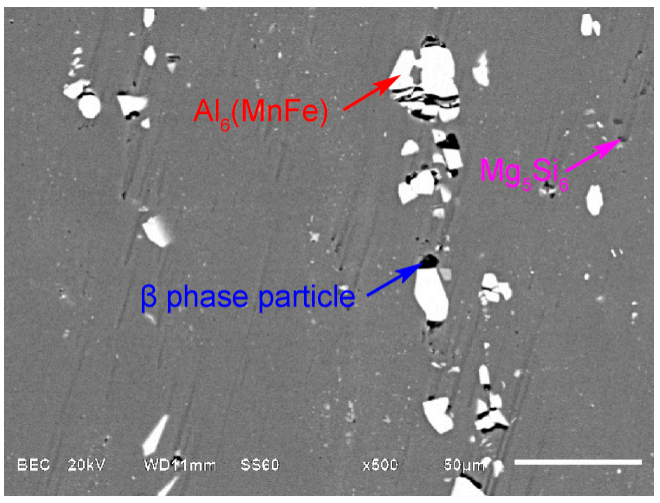

(a)

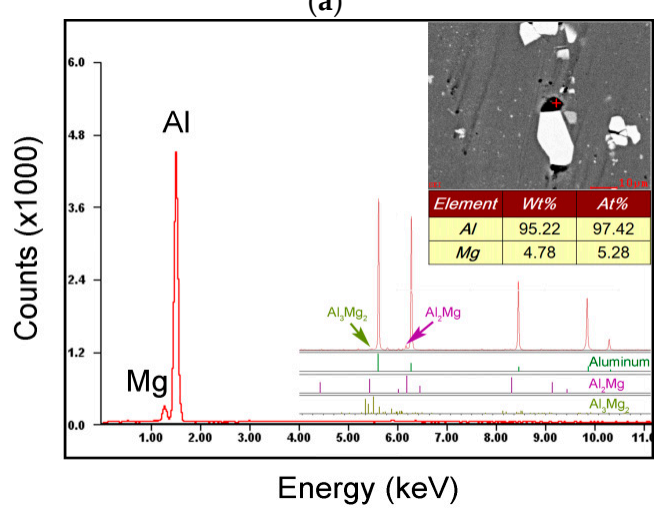

(c)

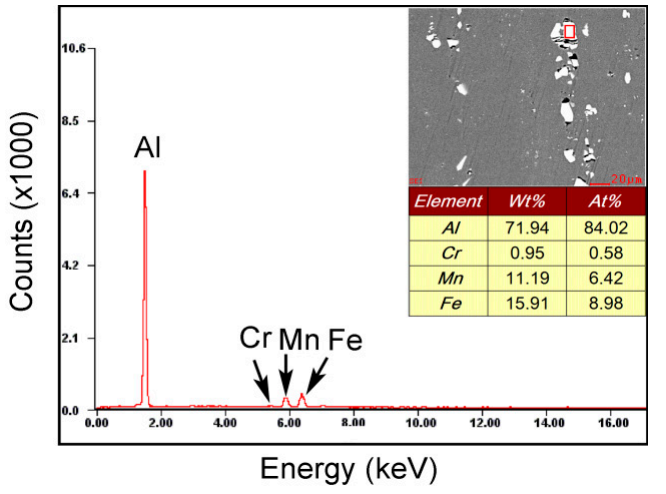

(b)

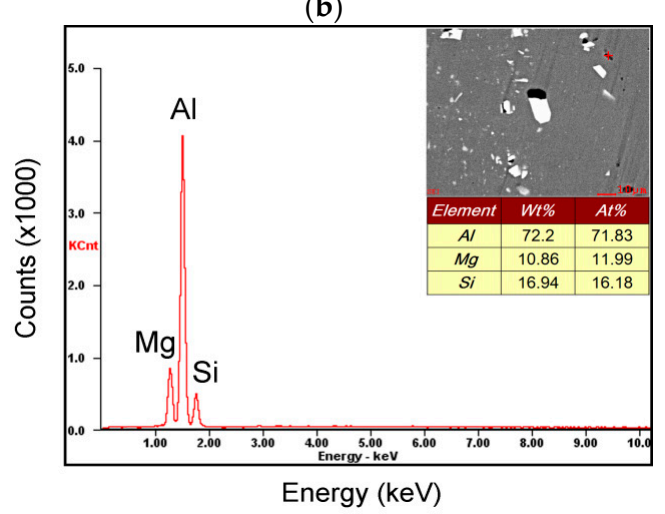

(d)

Figure 11. Formation and composition of the dispersed phase particle morphology at full recrystallization (a), and the EDS/X-ray diffraction results of $\mathrm{Al}_{6}(\mathrm{Mn}, \mathrm{Fe})$ phase $(\mathbf{b}), \beta$ phase $(\mathbf{c})$, and $\mathrm{Mg}_{5} \mathrm{Si}_{6}$ phase (d). 
Precipitation hardening, where small particles inhibit the movement of dislocations to strengthen aluminum alloys, was used to improve the mechanical strength of Al-Mg alloys. The composition and structure of the $\mathrm{Mg}_{5} \mathrm{Si}_{6}$ phase in aluminum alloys were determined, which occurred as precipitates, and were associated with a particularly strong increase in the mechanical strength. This was due to the magnesium content increasing to $5.72 \mathrm{wt} . \%$, while the addition of $\mathrm{Mn}, \mathrm{Fe}, \mathrm{Cr}$, and $\mathrm{Si}$ improved the nucleation of the second phase particles $[69,70]$. However, the dynamic recrystallization was intensely impacted by the increased temperatures, and the dispersed distribution of the precipitated phases effectively impeded the grain growth and promoted the equiaxial transformation of the fine-grained structure, as shown in Figure 10. At $550{ }^{\circ} \mathrm{C}$ and $1 \times 10^{-3} \mathrm{~s}^{-1}$, the inhibiting effect on the grain growth during tensile of the dynamic recrystallization decreased significantly when the grain size was $21.16 \mu \mathrm{m}$, as shown in Figure 10d. The abnormal grain growth resulted in an increase of the true stress under strain hardening (Figure $4 \mathrm{~b}$ ). The pinning effect of the precipitate was the intrinsic mechanism for the change in the true stress-true strain during the superplastic deformation and had a positive effect on the cavity nucleation and growth.

At $500{ }^{\circ} \mathrm{C}$ and $1 \times 10^{-3} \mathrm{~s}^{-1}$, when the accumulated applied stress reached a maximum during the superplastic tensile, it was found that sliding of the grain boundary under the shear stress caused dislocations to pin up at the head of the phase particles, as shown in Figure 12a, and the cross grain boundaries slid and climbed to form a sub-grain boundary, as shown in Figure 12b. The TEM results suggest that the dislocation density in the fine-grained structure of the 5A70 alloy during superplastic deformation was $\sim 5 \times 10^{-14} \mathrm{~m}^{2}$. In addition, the dislocations gradually moved towards and were absorbed by the sub-grain boundaries during superplastic deformation. When the pile-up stress, $\sigma_{p}$, exceeded the theoretical decohesion strength of the Al-matrix/second phase particle interface boundary), the cavity began to nucleate [36]. At $500{ }^{\circ} \mathrm{C}$ and $1 \times 10^{-3} \mathrm{~s}^{-1}$, the maximum applied stress $\left(\sigma_{\max }=3.75 \mathrm{MPa}\right)$ is substituted for the typical product stress $\sigma_{p}=7.87 \mathrm{MPa}$ [71]. Since the plugging stress threshold was more than twice the applied stress during superplastic tensile, the Al-matrix and the strengthening phase particles were easily separated and promoted cavity nucleation.

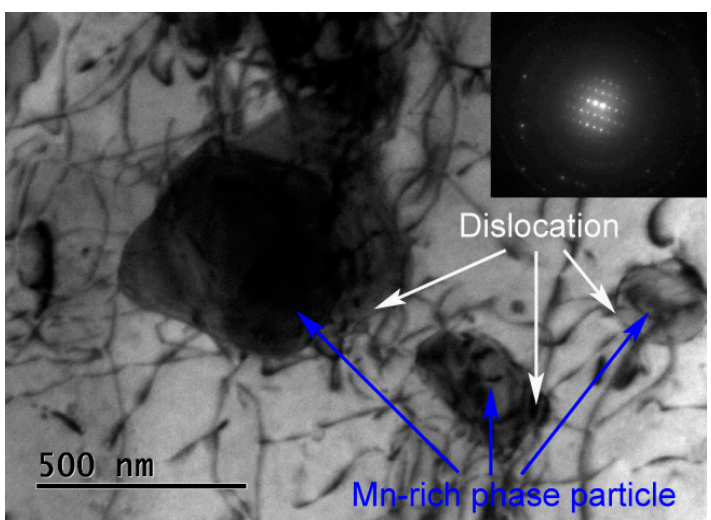

(a)

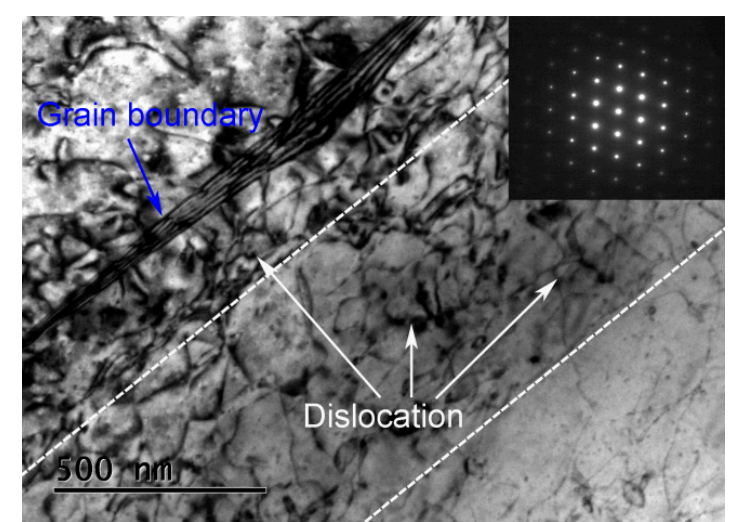

(b)

Figure 12. Location of dislocations, precipitated particles (a), and grain boundaries (b) in TEM images at $T=500{ }^{\circ} \mathrm{C}$ and $\dot{\varepsilon}=1 \times 10^{-3} \mathrm{~s}^{-1}$ with $\varepsilon=0.65$.

The cavity nucleation and growth mechanism of the superplastic tensile was the cavity growth of stress promoting the diffusion of the small cavity along the grain boundary, including the superplastic diffusion growth, and the plastic-controlled growth caused by the plastic deformation of the recrystallized grain around the cavity [72]. The pinning effect of the precipitated phase enhanced the cavity nucleation and the chemical potential between the forceful grain boundary atoms and the free surface of the cavity at $550{ }^{\circ} \mathrm{C}$ [73].

Cavity expansion mainly occurred during the growth of the diffusion and the superplastic diffusion because of the spreading of voids into the nearby cavity since the cavity radius was less than the grain size. In addition, plastic-controlled growth dominated the cavity interlinkage and 
coalescence process, which eventually led to superplastic fracturing [74]. The expansion of the cracks was the fundamental reason for the transient instability and superplastic fracture. The behavior of cavities nearby the fracture surface was studied, as shown in Figure 13, which illustrates the fracture morphology of the superplastic tensile specimens.

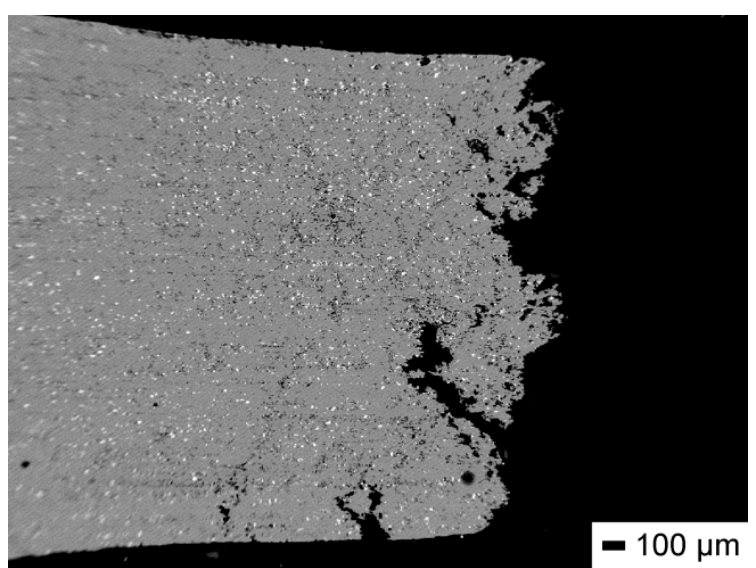

(a)

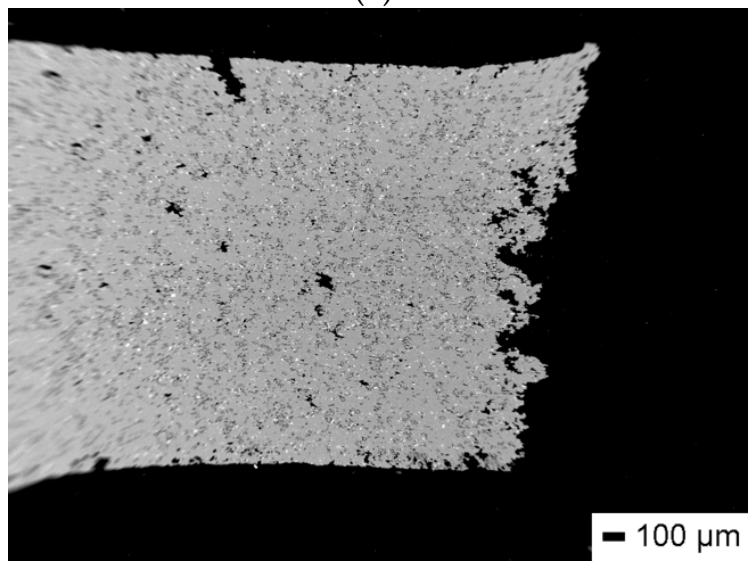

(c)

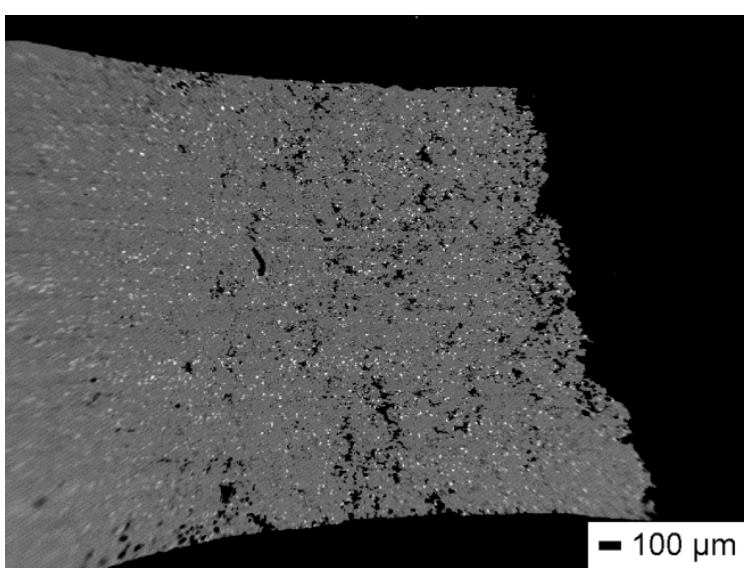

(b)

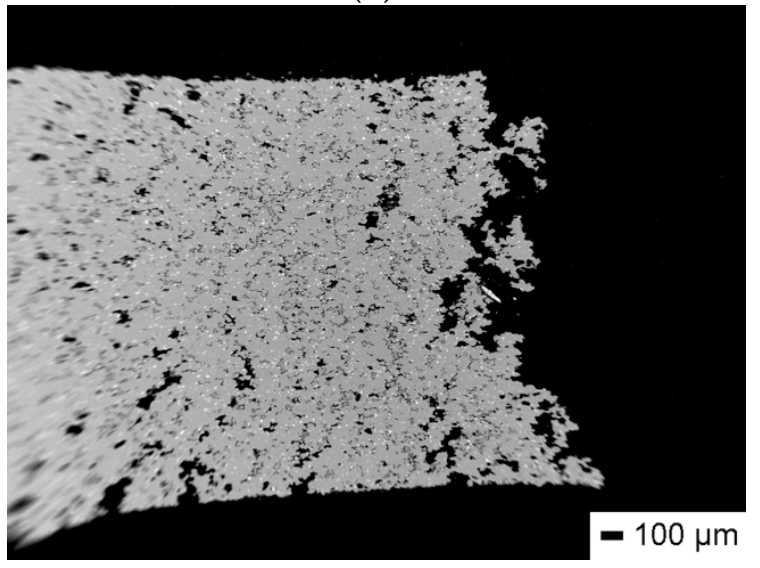

(d)

Figure 13. Fracture morphologies and cavity behaviors for the superplastic fraction surfaces of the 5A70 alloy at $T=400{ }^{\circ} \mathrm{C}, \dot{\varepsilon}=1 \times 10^{-3} \mathrm{~s}^{-1}(\mathbf{a}) ; T=450{ }^{\circ} \mathrm{C}, \dot{\varepsilon}=1 \times 10^{-3} \mathrm{~s}^{-1}$ (b); $T=500{ }^{\circ} \mathrm{C}, \dot{\varepsilon}=5 \times 10^{-4} \mathrm{~s}^{-1}$ (c); and $T=550^{\circ} \mathrm{C}, \dot{\varepsilon}=5 \times 10^{-4} \mathrm{~s}^{-1}$ (d).

Figure 13a-d show that no significant necking occurred at the superplastic fracture, and cracks near the fracture location gradually spread outwards from the fracture along the accumulated deformation. Therefore, crack formation was the main reason for the ultimate fracture of superplastic tensile [75]. The pinning effect of the phase particles was strengthened to enhance the cavity nucleation and the chemical potential between the forceful grain boundary atoms and the free surface of the cavity. In a previous study, the results demonstrated a clear transition from diffusion growth to superplastic diffusion growth and plastic-controlled growth at a cavity radius larger than 1.52 and $13.90 \mu \mathrm{m}$ [71]. Cavity growth mainly occurred at the stage of diffusion growth and superplastic diffusion growth due to the diffusion of the voids into adjacent cavities with a cavity radius smaller than the grain size. Plastic-controlled growth dominated the cavity interlinkage and coalescence process, which eventually led to superplastic fractures. Therefore, the irregular-shaped cavity with the accumulation of deformation strains induced wedge cracks, which propagated and converged under the shear stresses until a fracture occurred.

At the first stage, the crack in the specimen propagated as an opening mode crack that formed vortex structures (Figure 7). Second phase particles were formed along the cavity surface, which indicates a high mass transfer rate in the vortex porous structure. At the second stage, periodic 
transverse shear displacement occurred at the fracture surface (Figure 13b,c) due to a change of the crack type: the crack at this stage propagated as a sliding mode crack. As the crack reached the specimen edges, it rotated and propagated along the direction of $\tau_{\max }$ under plane stresses. At this stage, the fracture fractograph revealed traces of material rotations along the longitudinal shear in the form of plane cavities and discontinuities (Figure 13d) [76].

At $550{ }^{\circ} \mathrm{C}$, the dissolution of the phase particles reduced the suppression of grain growth during dynamic recrystallization. However, the grain growth promoted the healing of the small cavities [71]. This clearly verifies that the cavity nucleation and cavity growth during superplastic tensile deformation promoted steady-state flows. Ultimately, the cracks destroyed the superplastic tensile stability and resulted in superplastic fracturing with no obvious necking.

\section{Conclusions}

The following conclusions are drawn from this work:

(1) Static recrystallization at $340^{\circ} \mathrm{C}$ for $20 \mathrm{~min}$ showed an average grain size of $8.48 \mu \mathrm{m}$ for the $2 \mathrm{~mm}$ thick 5A70 alloy sheet, which was due to the pinning effect from the dispersion of the second phase particles.

(2) The 5 A70 aluminum alloy exhibited reasonable $\delta$ values at $400{ }^{\circ} \mathrm{C}(205 \%)$ and $450{ }^{\circ} \mathrm{C}(321 \%)$ with a moderate strain rate $\left(1 \times 10^{-3} \mathrm{~s}^{-1}\right)$, while the corresponding coefficients for the strain rate sensitivity, $m$, were 0.42 and 0.40 , respectively. However, excellent $\delta$ values were obtained with a low strain rate of $5 \times 10^{-4} \mathrm{~s}^{-1}$ at $500(398 \%)$ and $550{ }^{\circ} \mathrm{C}(437 \%)$ with $m=0.47$ and 0.46 , respectively.

(3) The strain hardening of the 5A70 alloy preferentially occurred at high temperatures (500 and $550^{\circ} \mathrm{C}$ ) with low strain rates $\left(5 \times 10^{-4} \mathrm{~s}^{-1}\right)$. This was due to the decreased $\mathrm{Mg}$-rich phase particles, and the abnormal grain growth weakened the pinning effect during dynamic recrystallization.

(4) The activation energy at $400-550{ }^{\circ} \mathrm{C}$ ranged from 135 to $139 \mathrm{~kJ} / \mathrm{mol}$, which is close to the lattice diffusion activation energy of pure aluminum $(143.4 \mathrm{~kJ} / \mathrm{mol})$. Therefore, lattice diffusion dominated the GBS mechanism of the 5A70 alloy during superplastic deformation.

(5) Massive second phase particles played a significant effect in suppressing the dynamic recrystallization during superplastic tensile and promoted the cavity nucleation, growth, interlinkage, and coalescence during superplastic deformation.

(6) The formation of submicrometer filaments at the fraction surfaces were due to the Mg-rich phase particles that precipitated along the grain boundaries in the GBS and from the growth of $\mathrm{MgO}$ and $\mathrm{MgAl}_{2} \mathrm{O}_{4}$ that formed at high temperatures during superplastic formation.

Author Contributions: Conceptualization, Z.H. and S.L.; methodology, S.L.; software, S.L.; validation, Z.H., S.J., and S.L.; formal analysis, S.L.; investigation, S.L.; resources, Z.H. and S.J.; data curation, S.L.; writing-original draft preparation, S.L.; writing—review and editing, S.L.; supervision, H.Z.; project administration, S.J.; funding acquisition, S.J.

Funding: This research was funded by the Fundamental Research Funds for the Central Universities of China, grant number FRF-TP-16-043Al and the APC was funded by S.J.

Acknowledgments: We would like to thank Guoliang Xie for help in material preparation, Xuetong Zhao for assistance in the superplastic tensile tests, Shuming Wang for assistance in the SEM/EBSD analysis, and Xinqin Liu for help analyzing the result.

Conflicts of Interest: The authors declare no conflict of interest.

\section{References}

1. Bolt, P.J.; Lamboo, N.A.P.M.; Rozier, P.J.C.M. Feasibility of warm drawing of aluminium products. J. Mater. Process. Technol. 2001, 115, 118-121. [CrossRef]

2. Naka, T.; Torikai, G.; Hino, R.; Yoshida, F. The effects of temperature and forming speed on the forming limit diagram for type 5083 aluminum-magnesium alloy sheet. J. Mater. Process. Technol. 2001, 113, 648-653. [CrossRef] 
3. Lin, S.P.; Nie, Z.R.; Huang, H.; Li, B.L. Annealing behavior of a modified 5083 aluminum alloy. Mater. Des. 2010, 31, 1607-1612. [CrossRef]

4. Popović, M.; Romhanji, E. Stress corrosion cracking susceptibility of Al-Mg alloy sheet with high Mg content. J. Mater. Process. Technol. 2002, 125-126, 275-280. [CrossRef]

5. Tokuda, M.; Inaba, T.; Ohigashi, H.; Kurakake, A. Discussions on constitutive equations of superplastic 5083 aluminum alloy. Int. J. Mech. Sci. 2001, 43, 2035-2046. [CrossRef]

6. Langdon, T.G. Seventy-five years of superplasticity: Historic developments and new opportunities. J. Mater. Sci. 2009, 44, 5998-6010. [CrossRef]

7. Iwahashi, Y.; Horita, Z.; Nemoto, M.; Langdon, T.G. Factors influencing the equilibrium grain size in equal-channel angular pressing: Role of Mg additions to aluminum. Metall. Mater. Trans. A 1998, 29, 2503-2510. [CrossRef]

8. Portnoy, V.K.; Rylov, D.S.; Levchenko, V.S.; Mikhaylovskaya, A.V. The influence of chromium on the structure and superplasticity of Al-Mg-Mn alloys. J. Alloys Compd. 2013, 581, 313-317. [CrossRef]

9. Woo, S.S.; Kim, Y.R.; Shin, D.H.; Kim, W.J. Effects of Mg concentration on the quasi-superplasticity of coarse-grained Al-Mg alloys. Scr. Mater. 1997, 37, 1351-1358. [CrossRef]

10. Kishchik, A.A.; Mikhaylovskaya, A.V.; Levchenko, V.S.; Portnoy, V.K. Formation of microstructure and the superplasticity of Al-Mg-based alloys. Phys. Met. Metallogr. 2017, 118, 96-103. [CrossRef]

11. Chang, S.Y.; Lee, J.G.; Park, K.T.; Shin, D.H. Microstructures and Mechanical Properties of Equal Channel Angular Pressed 5083 Al Alloy. Mater. Trans. 2001, 42, 1074-1080. [CrossRef]

12. Patlan, V.; Higashi, K.; Kitagawa, K.; Vinogradov, A.; Kawazoe, M. Cyclic Response of Fine Grain 5056 Al-Mg Alloy Produced by Equal Channel Angular Pressing. Mater. Sci. Eng. A 2001, 319-321, 587-591. [CrossRef]

13. Patlan, V.; Vinogradov, A.; Higashi, K.; Kitagawa, K. Overview of fatigue properties of fine grain $5056 \mathrm{Al}-\mathrm{Mg}$ alloy processed by equal channel angular pressing. Mater. Sci. Eng. A 2001, 300, 171-182. [CrossRef]

14. Yamashita, A.; Yamaguchi, D.; Horita, Z.; Langdon, T.G. Influence of pressing temperature on microstructural development in equal-channel angular pressing. Mater. Sci. Eng. A 2000, 287, 100-106. [CrossRef]

15. Fakhar, N.; Saniee, F.F.; Mahmudi, R. Significant improvements in mechanical properties of AA5083 aluminum alloy using dual equal channel lateral extrusion. Trans. Nonferrous Met. Soc. China 2016, 26, 3081-3090. [CrossRef]

16. Park, K.T.; Hwang, D.Y.; Lee, Y.K.; Kim, Y.K.; Shi, D.H. High strain rate superplasticity of submicrometer grained $5083 \mathrm{Al}$ alloy containing scandium fabricated by severe plastic deformation. Mater. Sci. Eng. A 2003, 341, 273-281. [CrossRef]

17. Charit, I.; Mishra, R.S. Evaluation of microstructure and superplasticity in friction stir processed $5083 \mathrm{Al}$ alloy. J. Mater. Res. 2004, 19, 3329-3342. [CrossRef]

18. Charit, I.; Mishra, R.S. High strain rate superplasticity in a commercial $2024 \mathrm{Al}$ alloy via friction stir processing. Mater. Sci. Eng. A 2003, 359, 290-296. [CrossRef]

19. Ma, Z.Y.; Mishra, R.S.; Mahoney, M.W. Superplastic deformation behaviour of friction stir processed $7075 \mathrm{Al}$ alloy. Acta Mater. 2002, 50, 4419-4430. [CrossRef]

20. Mahoney, M.W.; Barnes, A.J.; Bingel, W.H.; Fuller, C.B. Superplastic Forming of 7475 Al Sheet after Friction Stir Processing (FSP). Mater. Sci. Forum 2004, 447-448, 505-512. [CrossRef]

21. Salem, H.G.; Reynolds, A.P.; Lyons, J.S. Structural evolution and superplastic formability of friction stir welded AA 2095 sheets. J. Mater. Eng. Perform. 2004, 13, 24-31. [CrossRef]

22. Sato, E.; Itoh, G.; Takayama, Y.; Kitazono, K.; Morita, K.; Itoi, T.; Kobayashi, J. Superplastic Behavior of Friction Stir Welded Joints of an Al-Mg-Sc Alloy with Ultrafine Grained Microstructure. Mater. Sci. Forum 2016, 838-839, 338-343. [CrossRef]

23. Mironov, S.; Malopheyev, S.; Vysotskiy, I.; Kaibyshev, R. Superplasticity of Friction-Stir Welds of Zr-Modified 5083 Aluminum Alloy with Ultrafine-Grained Structure. Defect Diffus. Forum 2018, 385, 15-20. [CrossRef]

24. Beijing Institute of Aeronautical Materials Group. Materials Technology of Aeronautics; Aviation Industry Press: Beijing, China, 2014; pp. 131-143, ISBN 978-7-5165-0298-3.

25. Nieh, T.G.; Wadsworth, J.; Sherby, O.D. Superplasticity in Metals and Ceramics; Cambridge University Press: Cambridge, UK, 1997; pp. 22-30, ISBN 978-0-521-02034-3.

26. Yuzbekova, D.; Mogucheva, A.; Kaibyshev, R. Superplasticity of ultrafine-grained Al-Mg-Sc-Zr alloy. Mater. Sci. Eng. A 2016, 675, 228-242. [CrossRef] 
27. Ota, S.; Akamatsu, H.; Neishi, K.; Furukawa, M.; Horita, Z.; Langdon, T.G. Low-Temperature Superplasticity in Aluminum Alloys Processed by Equal-Channel Angular Pressing. Mater. Trans. 2002, 43, 2364-2369. [CrossRef]

28. Xun, Y.W.; Mohamed, F.A. Superplastic behavior of $\mathrm{Zn}-22 \% \mathrm{Al}$ containing nanoscale dispersion particles. Acta Mater. 2004, 52, 4401-4412. [CrossRef]

29. Prabu, S.B.; Padmanabhan, K.A. Superplasticity in and Superplastic Forming of Aluminum-Lithium Alloys. In Aluminum-Lithium Alloy, Processing, Properties, and Applications; Prasad, N.E., Gokhale, A.A., Wanhill, R.J., Eds.; Elsevier: Oxford, UK, 2014; Volume 8, pp. 221-258, ISBN 978-0-12-401698-9.

30. Lee, S.W.; Yeh, J.W. Superplasticity of 5083 alloys with $\mathrm{Zr}$ and Mn additions produced by reciprocating extrusion. Mater. Sci. Eng. A 2007, 460-461, 409-419. [CrossRef]

31. Langdon, T.G. A unified approach to grain boundary sliding in creep and superplasticity. Acta Metall. Mater. 1994, 42, 2437-2443. [CrossRef]

32. Stato, Y.S.; Park, S.H.C.; Michiuchi, M.; Kokawa, H. Constitutional liquation during dissimilar friction stir welding of $\mathrm{Al}$ and Mg alloys. Scr. Mater. 2004, 50, 1233-1236. [CrossRef]

33. Li, S.; Huang, Z.G.; Jin, S.Y.; Wang, B.Y.; Liu, X.Q.; Lei, K. Heat Treatment Process of Cold Rolled 5A70 Aluminum alloy Superplastic Sheet. Chin. J. Rare Met. 2018, 42, 283-288. [CrossRef]

34. Horita, Z.; Furukawa, M.; Nemoto, M.; Barnes, A.J.; Langdon, T.G. Superplastic forming at high strain rates after severe plastic deformation. Acta Mater. 2000, 48, 3633-3640. [CrossRef]

35. Smolej, A.; Klobčar, D.; Skaza, B.; Nagode, A.; Slaček, E.; Dragojević, V.; Smolej, S. Superplasticity of the rolled and friction stir processed Al-4.5 Mg-0.35Sc-0.15Zr alloy. Mater. Sci. Eng. A 2014, 590, 239-245. [CrossRef]

36. Lee, S.; Utsunomiya, A.; Akamatsu, H.; Neishi, K.; Furukawa, M.; Horita, Z.; Langdon, T.G. Influence of scandium and zirconium on grain stability and superplastic ductilities in ultrafine-grained $\mathrm{Al}-\mathrm{Mg}$ alloys. Acta Mater. 2002, 50, 553-564. [CrossRef]

37. Mikhaylovskaya, A.V.; Yakovtseva, O.A.; Golovin, I.S.; Pozdniakov, A.V.; Portnoy, V.K. Superplastic deformation mechanisms in fine-grained Al-Mg based alloys. Mater. Sci. Eng. A 2015, 627, 31-41. [CrossRef]

38. Kulas, M.A.; Green, W.P.; Taleff, E.M.; Krajewski, P.E.; Mcnelley, T.R. Deformation mechanisms in superplastic AA5083 materials. Metall. Mater. Trans. A 2005, 36, 1249-1261. [CrossRef]

39. Yavari, P.; Langdon, T.G. An examination of the breakdown in creep by viscous glide in solid solution alloys at high stress levels. Acta Mater. 1982, 30, 2181-2196. [CrossRef]

40. McNalley, T.R.; Michel, D.J.; Salama, A. The Mg-concentration dependence of the strength of Al-Mg alloys during glide-controlled deformation. Scr. Metall. 1989, 23, 1657-1662. [CrossRef]

41. Gali, O.A.; Riahi, A.R.; Alpas, A.T. The effect of surface conditions on the elevated temperature sliding contact deformation of AA5083 alloy. Wear 2015, 330-331, 309-319. [CrossRef]

42. Cao, F.R.; Li, Z.L.; Zhang, N.X.; Ding, H.; Yu, F.X.; Zuo, L. Superplasticity, flow and fracture mechanism in an Al-12.7Si-0.7Mg alloy. Mater. Sci. Eng. A 2013, 571, 167-183. [CrossRef]

43. Shin, D.H.; Park, K.T. Directional cavity stringer formation in a superplastic $7075 \mathrm{Al}$ alloy. Mater. Sci. Eng. A 1999, 268, 55-62. [CrossRef]

44. Blandin, J.J.; Hong, B.; Varloteaux, A.; Suery, M.; L'Esperance, G. Effect of the nature of grain boundary regions on cavitation of a superplastically deformed aluminium alloy. Acta Mater. 1996, 44, 2317-2326. [CrossRef]

45. Zelin, M.G. On micro-superplasticity. Acta Mater. 1997, 45, 3533-3542. [CrossRef]

46. Tan, J.C.; Tan, M.J. Superplasticity and grain boundary sliding characteristics in two stage deformation of Mg-3Al-1Zn alloy sheet. Mater. Sci. Eng. A 2003, 399, 81-89. [CrossRef]

47. Ritchie, I.M.; Sanders, J.V.; Weickhardt, P.L. Oxidation of a dilute aluminum magnesium alloy. Oxid. Met. 1971, 3, 91-101. [CrossRef]

48. Chang, J.K.; Taleff, E.M.; Krajewski, P.E.; Ciulik, J.R. Effects of atmosphere in filament formation on a superplastically deformed aluminum-magnesium alloy. Scr. Mater. 2009, 60, 459-462. [CrossRef]

49. Dirras, G. Filament formation during elevated temperature deformation of high purity ultrafine-grained aluminum. Mater. Lett. 2010, 64, 1163-1165. [CrossRef]

50. Das, S.; Riahi, A.R.; Meng-Burany, X.; Morales, A.T.; Alpas, A.T. High temperature deformation and fracture of tribo-layers on the surface of AA5083 sheet aluminum-magnesium alloy. Mater. Sci. Eng. A 2012, 531, 76-83. [CrossRef] 
51. Taleff, E.M.; Nevland, P.J.; Krajewski, P.E. Tensile ductility of several commercial aluminum alloys at elevated temperatures. Metall. Mater. Trans. A 2001, 32, 1119-1130. [CrossRef]

52. Kaibyshev, R.; Sakai, T.; Nikulin, I.; Musin, F.; Goloborodko, A. Superplasticity in a 7055 aluminum alloy subjected to intense plastic deformation. Mater. Sci. Technol. 2003, 19, 1491-1497. [CrossRef]

53. Valiev, R.Z. Structure and mechanical properties of ultrafine-grained metals. Mater. Sci. Eng. A 1997, 234-236, 59-66. [CrossRef]

54. Mohamed, F.A. Interpretation of superplastic flow in terms of a threshold stress. J. Mater. Sci. 1983, 8, 582-592. [CrossRef]

55. Ma, Z.Y.; Liu, F.C.; Mishra, R.S. Superplastic deformation mechanism of an ultrafine-grained aluminum alloy produced by friction stir processing. Acta Mater. 2010, 58, 4693-4704. [CrossRef]

56. Watanabe, H.; Mukai, T.; Kohzu, M.; Tanabe, S.; Higashi, K. Effect of temperature and grain size on the dominant diffusion process for superplastic flow in an AZ61 magnesium alloy. Acta Mater. 1999, 47, 3753-3758. [CrossRef]

57. Sakai, T.; Miura, H.; Goloborodko, A.; Sitdikov, O. Continuous dynamic recrystallization during the transient severe deformation of aluminum alloy 7475. Acta Mater. 2009, 57, 153-162. [CrossRef]

58. Mao, W.; Yu, Y. Effect of elastic reaction stress on plastic behaviors of grains in polycrystalline aggregate during tensile deformation. Mater. Sci. Eng. A 2004, 367, 277-281. [CrossRef]

59. Sato, E.; Kuribayashi, K. Superplasticity and Deformation Induced Grain Growth. ISIJ Int. 1993, 33, 825-832. [CrossRef]

60. Cao, F.R.; Lei, F.; Cui, J.Z.; Wen, J.L. Modification of a deformation induced grain growth model of superplasticity and its experimental verification. Acta Metall. Sin. 1999, 35, 770-772.

61. Cao, F.R.; Ding, H.; Li, Y.L.; Zhou, G.; Cui, J.Z. Superplasticity, dynamic grain growth and deformation mechanism in ultra-light two-phase magnesium-lithium alloys. Mater. Sci. Eng. A 2010, 527, 2335-2341. [CrossRef]

62. Malopheyev, S.; Kipelova, A.; Nikulin, I.; Kaibyshev, R. Mechanical Properties of an Al-5.4\%Mg-0.5\%Mn- $0.1 \% Z r$ Alloy Subjected to ECAP and Rolling. Mater. Sci. Forum 2011, 667-669, 815-820. [CrossRef]

63. Cao, F.R.; Cui, J.Z.; Wen, J.L.; Lei, F. Mechanical Behaviour and Microstructure Evolution of Superplastic Mg-8.4 wt pct Li Alloy and Effect of Grain Size and Phase Ratio on Its Elongation. J. Mater. Sci. Technol. 2000, 16, 55-58.

64. Cao, F.R. Metal Superplasticity; Metallurgical Industry Press: Beijing, China, 2014; pp. 211-212, ISBN 978-7-5024-6690-9.

65. Jie, J.C.; Zou, C.M.; Wang, H.W.; Li, B.; Wei, Z.J. Enhancement of mechanical properties of Al-Mg alloy with a high Mg content solidified under high pressures. Scr. Mater. 2011, 64, 588-591. [CrossRef]

66. Wang, G.S.; Liu, K.; Wang, S.L. Evolution of Elevated-Temperature Strength and Creep Resistance during Multi-Step Heat Treatments in Al-Mn-Mg Alloy. Materials 2018, 11, 1158. [CrossRef] [PubMed]

67. Zandbergen, H.W.; Andersen, S.J.; Jansen, J. Structure determination of $\mathrm{Mg}_{5} \mathrm{Si}_{6}$ particles in $\mathrm{Al}$ by dynamic electron diffraction studies. Science 1997, 277, 1221-1225. [CrossRef]

68. Wang, Y.; Liu, Z.K.; Chen, L.Q.; Wolverton, C. First-principles calculations of $\beta$ "- $\mathrm{Mg}_{5} \mathrm{Si}_{6} / \alpha$-Al interfaces. Acta Mater. 2007, 55, 5934-5947. [CrossRef]

69. Zhang, J.C.; Ding, D.Y.; Zhang, W.L.; Kang, S.H.; Xu, X.L.; Gao, Y.J.; Chen, G.Z.; Chen, W.G.; You, X.H. Effect of $\mathrm{Zr}$ addition on microstructure and properties of Al-Mn-Si-Zn-based alloy. Trans. Nonferrous Met. Soc. China 2014, 24, 3872-3878. [CrossRef]

70. Seifeddine, S.; Svensson, I.L. Prediction of mechanical properties of cast aluminium components at various iron contents. Mater. Des. 2010, 31, 6-12. [CrossRef]

71. Li, S.; Huang, Z.G.; Jin, S.Y. Cavity Behavior of Fine-Grained 5A70 Aluminum Alloy during Superplastic Formation. Metals 2018, 8, 1065. [CrossRef]

72. Bae, D.H.; Ghosh, A.K. Cavity growth during superplastic flow in an Al-Mg alloy: I. Experimental study. Acta Mater. 2002, 50, 993-1009. [CrossRef]

73. Takigawa, Y.; Aguirre, J.V.; Taleff, E.M.; Higashi, K. Cavitation during grain-boundary-sliding deformation in an AZ61 magnesium alloy. Mater. Sci. Eng. A 2008, 497, 139-146. [CrossRef]

74. Kawasaki, M.; Xu, C.; Langdon, T.G. An investigation of cavity growth in a superplastic aluminum alloy processed by ECAP. Acta Mater. 2005, 53, 5353-5364. [CrossRef] 
75. Fan, G.J.; Choo, H.; Liaw, P.K.; Lavernia, E.J. Plastic deformation and fracture of ultrafine-grained Al-Mg alloys with a bimodal grain size distribution. Acta Mater. 2006, 54, 1759-1766. [CrossRef]

76. Panin, V.E.; Egorushkin, V.E.; Derevyagina, L.S.; Deryugin, E.E. Nonlinear wave processes of crack propagation in brittle and brittle-ductile fracture. Phys. Mesomech. 2013, 16, 183-190. [CrossRef]

(C) 2019 by the authors. Licensee MDPI, Basel, Switzerland. This article is an open access article distributed under the terms and conditions of the Creative Commons Attribution (CC BY) license (http://creativecommons.org/licenses/by/4.0/). 